\title{
GERICHTSVERFASSUNG UND RECHTSAUFFASSUNG IM PROGRESSISTISCHEN GUINEA
}

\author{
Von JoAchim Voss
}

\section{Was für eine Justiz?}

Im Januar 1971 fand in Conakry, der Hauptstadt der westafrikanischen Republik Guinea, ein politischer Monsterprozeß statt, der die deutsche Offentlichkeit zwar nicht wegen der 91 Todesurteile gegen Guineer bewegte, aber immerhin deshalb, weil die Bundesrepublik Deutschland mit auf der Anklagebank saß und zwei ihrer Bürger (davon beging einer angeblich Selbstmord) wegen angeblicher Beteiligung an den Novemberereignissen des Jahres 1970 (Invasion Guineas durch exilguineische Gegner des Präsidenten Sékou Touré im Verein mit regulären portugiesischen Truppen) zu lebenslänglicher Zwangsarbeit verurteilt wurden. Bei dieser Gelegenheit erfuhr die deutsche Ơffentlichkeit mehr über den fernen jakobinisch-marxistischen Revolutionsstaat Sékou Tourés als in zwölf Jahren nicht ganz uneigennütziger Entwicklungshilfe zuvor. Ebenfalls im Januar 1971 war Yaoundé, eine andere afrikanische Hauptstadt, Schauplatz politischer Strafprozesse gegen Feinde eines ungeliebten Regimes. Es waren dies Prozesse, die wegen der Todesurteile gegen den weit über Kameruns Grenzen hinaus geachteten Ernest Ouandi (den 2. Vorsitzenden der verbotenen Oppositionspartei U.P.C.) und Mgr. Ndongmo, den Bischof von Nkongsamba, ein weltweites Echo fanden. So war die Möglichkeit gegeben, einige Unterschiede festzustellen. Das Verfahren in Yaoundé fand vor dem dortigen Ständigen Militärgerichtshof, also immerhin vor einem Gericht und im Beisein qualifizierter internationaler Beobachter statt, die dem Prozeß hinterher einen Ablauf „unter normalen Bedingungen“ bescheinigten (so z. B. M. Pettiti, Mitglied der frz. Anwaltskammer und Vertreter der Internationalen Vereinigung Katholischer Juristen). Präsident Ahidjo machte von seinem Gnadenrecht Gebrauch und wandelte wenigstens die Todesurteile gegen den Bischof und zwei weitere Angeklagte in lebenslange Freiheitsstrafen um. In Conakry war alles ganz anders. Qualifizierte internationale Beobachter fehlten, und der Prozeß fand nicht vor einem Ständigen, sondern vor einem ad hoc berufenen Gericht statt, und zwar vor dem Plenum der Nationalversammlung, die sich für ein paar Tage zum Revolutionstribunal konstituierte und ihre Urteile aufgrund von Strafanträgen fällte, die nicht vom Generalstaatsanwalt der Republik gestellt worden waren, sondern von Volksversammlungen, die die regierende Einheitspartei in der Woche davor landauf, landab organisiert hatte. Hier also - wenigstens dem Anschein nach - fast plebiszitäre Volksjustiz, dort autoritäre Militärjustiz, welch letztere im allgemeinen als die denkbar härteste Form von Rechtsprechung gilt. Aber während der eine Gerichtsherr, Ahidjo (gewiß kein Demokrat), sich zu Gnadenakten bewegen ließ, hatte der andere Gerichtsherr, Sékou Touré, der "Premier Résponsable“ der guineischen Revolution, auf die Ausübung des ihm gleichfalls zustehenden Gnadenrechts ohne Not noch vor Beginn des Prozesses feierlich verzichtet. Und die Hinrichtung der zum Tode Verurteilten erfolgte zwar nicht durch "Sieden in O'l“, wie es in der Nationalversammlung gefordert worden war, aber auch nicht durch das noch relativ "humane" Erschießen (wie in Kamerun), sondern durch öffentliches, qualvolles Erhängen auf Märkten und Brük- 
ken zur Abschreckung und Erbauung der leicht lenkbaren Massen (Radio Conakry: „La foule crachait sur les cadavres . .."). Was ist das für eine Justiz? Selbst im progressistischen, d. h. aufgeklärten, Guinea scheint nach wie vor der von Cheik Anta Diop in "L'Afrique Noire Pré-Coloniale" (Paris 1960) beschriebene Rechtsdualismus des alten Afrika zu herrschen: „justice royale“ und „justice du cadi“. Die Verbrechen der Majestätsbeleidigung und des Hochverrats, d. h. sämtliche Staatsschutzsachen, gehören in die Alleinzuständigkeit der „justice royale“, d. h., übersetzt in die rauhe Wirklichkeit des progressistischen Entwicklungsstaates, in die ALLEINZUSTANDIGKEIT DER REVOLUTION, und das wiederum heißt: in die Alleinzuständigkeit ihres obersten Repräsentanten Sékou Touré. Wie Askia Mohammed „qui a tenu lui-même à juger tous ceux qui avaient participé au complot visant à le renverser du trône" (Ch. A. Diop a. a. O., S. 96 ff.), hatte er das Urteil über die Angeklagten, von denen viele als seine Freunde galten, bereits gesprochen (in einem von der Parteizeitung HOROYA veröffentlichten Poem "Adieu les traîtres“), noch ehe sich das "Tribunal Révolutionnaire" überhaupt konstituiert hatte, er, der Bundespräsident Heinemann, welcher telefonisch versuchte, den deutschen Angeklagten Adolf Marx zu retten, sagen ließ, es sei ihm nicht möglich, in ein schwebendes Verfahren einzugreifen . . . Was also ist das für eine Justiz? Die nachfolgenden Seiten sind der Versuch einer Antwort.

\section{Die Justizverwaltung}

\section{a) Die Organe der Rechtspflege}

Von einer Gerichtsverfassung als solcher zu sprechen, verbietet die dienende Stellung der Justiz im revolutionären Staat, ihre Einbettung in das „ensemble de l'Administration Guinéenne comme élément d'une entité indivisible“. Wie alle anderen Organe der Staatsmacht untersteht sie der „prééminence du Parti“, d. h. "der direkten Kontrolle durch die verschiedenen Instanzen der P.D.G."1.

Die in diesem Sinne durchgeführte nachkoloniale Justizreform stieß in der Ơffentlichkeit auf keinerlei Widerstand. Drei Gründe lassen sich dafür anführen:

1. Es gab bei Abzug der Franzosen keine guineische Richterschaft, die diese Reform in ihrem Standesinteresse getroffen hätte.

2. Auch die Kolonialmacht hatte nur selten eine reinliche Trennung zwischen Rechtsprechung und Staatsgewalt gewährleisten können.

3. Nach der Vorstellung des Afrikaners ist die Ausübung der richterlichen von der Ausübung der staatlichen und politischen Gewalt nicht zu trennen:

„En Afrique, un chef qui n'est plus capable de punir ne peut plus commander"."

Das Problem, das sich Guinea nach Erlangung der Unabhängigkeit stellte, war, wie viele andere Probleme, doppelter Natur. Einerseits mußte die durch den regellosen Abzug der französischen Justizbeamten in Frage gestellte Kontinuität der

1 Sékou Touré im Rechenschaftsbericht an den VII. Parteikongreß, Kankan, August 1963.

2 A. Gandolfi, L'Administration Territoriale en Afrique Noire de Langue Francaise (hektogr.), Aix-enProvence 1959, S. $117 \mathrm{ff}$. 
Rechtsprechung aufrechterhalten werden ${ }^{3}$. Andererseits galt es, dem Ansatz auf allen anderen Gebieten des öffentlichen Lebens folgend, auch im Bereich der Justiz eine möglichst totale "reconversion“ der Strukturen, Methoden und Denkgewohnheiten herbeizuführen.

Eine neue soziale und politische Ordnung, so argumentierten die Reformer, mache auch eine Neuordnung der Rechtsprechung erforderlich. Sie prägten die Devise: "Justice du peuple au service du peuple, à la portée du peuple."

Vor allem das letztere galt als wichtig. Denn die Rechtspflege war nicht eben eine der starken Seiten des Kolonialregimes gewesen. Der für Guinea zuständige Appellationsgerichtshof hatte sich in Dakar (Senegal), der Kassationsgerichtshof gar in Paris befunden. In Guinea selbst hatte es zwei Landgerichte („Tribunaux de Première Instance") mit dem Sitz in Conakry und Kankan gegeben, die aber für die große Masse der Rechtsuchenden nur unter erheblichen Mühen und Opfern $z u$ erreichen waren, ganz abgesehen von den relativ hohen Verfahrenskosten. Die 14 Amtsgerichte („Justices de Paix“) mit erweiterter bzw. beschränkter Zuständigkeit in Beyla, Boffa, Boké, Dabola, Forécariah, Kindia, Kissidougou, Kouroussa, Labé, Macenta, Mamou, N'Zérékoré, Pita und Siguiri rangen, wie die jährlichen Tätigkeitsberichte der Kolonialgouverneure an die Territorialversammlung zeigen, unablässig mit Personal- und Materialschwierigkeiten, waren also bei steigendem Anfall von Straf- wie Zivilsachen nur sehr bedingt arbeitsfähig 4 .

Neben diesen Gerichten des gemeinen Rechts ("droit commun") bestand - ausschließlich für Zivilsachen - eine Gerichtsbarkeit nach Eingeborenen- wie man auch sagte, nach Gewohnheitsrecht („Droit indigène“ oder "droit coutumier"). Ihre Instanzen genossen aber nur geringe Autorität. Schöpfungen des Kolonialregimes, die sie waren, in denen Kolonialbeamte oder deren Günstlinge den Vorsitz führten, wurden sie von der Bevölkerung als „Werkzeuge der Ungerechtigkeit, des Diebstahls und vor allem der Spaltung" gemieden.

Die ersten Maßnahmen des neuen Regimes hatten gleichwohl rein pragmatischen Charakter. Unter überstürzter Berufung von Prozeßagenten, Gerichtsvollziehern, Justizwachtmeistern und Protokollführern in die verwaisten Richterämter wurden die vorhandenen Gerichte wiedereröffnet.

Außerdem wurde zur Sichtbarmachung der mit der politischen Unabhängigkeit erworbenen Justizhoheit eine eigene Appellations- und Kassationsgerichtsbarkeit eingerichtet, der "Cour d'Appel“ und das "Tribunal Supérieur de cassation“, beide mit dem Sitz in Conakry.

Der „Cour d'Appel“5 fungiert seitdem als Berufungsinstanz gegen die Entscheidungen der „Tribunaux de Première Instance“ und der "Justices de Paix à Compétence étendue“. Der "Cour d'Appel“ ist mit drei Berufsrichtern besetzt. Einer von ihnen bekleidet das Amt des Gerichtspräsidenten. Sie treten, je nach Sachlage, entweder als Zivil- und Handelskammer oder als Strafkammer bzw. als Eröffnungskammer in Strafsachen zusammen. Bei der letzteren Kammer können auch Rechtsmittel gegen die Entscheidungen der Untersuchungsrichter bei den

3 Sämtliche Gerichte schlossen ihre Pforten. Richter und Justizbeamte verließen unter Mitnahme oder Vernichtung des Akten- und Archivmaterials das Land: Ils s'en allèrent en laissant derrière eux le néant" (Keita Fadiala in "Bulletin du Ministère de la Justice“, Nr. 1. Conakry 1966).

4 "Rapports sur la situation de la colonie (ab 1950: du territoire) et la marche des différents services au cours de l'exercice 1947-1956“, Jahresberichte, guineisches Nationalarchiv.

5 Ordonnance Nr. 4 v. 15 . Oktober 1958. 
erstinstanzlichen Gerichten eingelegt werden. Zur Aburteilung von Verbrechen tritt der "Cour d'Appel“ als Schwurgericht („Cour d'Assises“) zusammen, und $z$ war in der Besetzung mit drei Berufsrichtern und vier Geschworenen.

Dem „Cour d'Appel“ zugeordnet ist die direkt dem Justizminister unterstellte Generalstaatsanwaltschaft. Ihre Augabe ist es, vor den Obergerichten die Interessen der Gesellschaft und des Staates zu vertreten, über die korrekte Anwendung der Gesetze und der im Namen des Volkes ergangenen Gerichtsentscheidungen zu wachen, die Dienstaufsicht über sämtliche Gerichte auszuüben und für die Befolgung der Regierungsinstruktionen zu sorgen, soweit sie die Justiz betreffen.

Das „Tribunal Supérieur de Cassation"6 wird durch den auf fünf Berufsrichter erweiterten "Cour d'Appel“ gebildet und tritt nur ad hoc zusammen. Den Vorsitz führt der Präsident des "Cour d'Appel“. Seine Zuständigkeit ist doppelter Art. Gegenüber den letztinstanzlichen Entscheidungen der „Tribunaux de Première Instance", der "Justices de Paix" und des "Cour d'Assises" fungiert er als Kontrollinstanz. Er kann hier lediglich die Rechtmäßigkeit der Entscheidungen nachprüfen. Sind diese unter Verletzung geltenden Rechts zustande gekommen, oder stellen sie selbst eine solche dar, dann hebt er sie auf und verweist die Sache zur erneuten Verhandlung an ein anderes Gericht gleichen Ranges.

Reformationsinstanz ist das Kassationsgericht gegenüber den Entscheidungen der Kammern des "Cour d'Appel“. Hier ist die Aufhebung auch aus tatsächlichen Gründen möglich. Geschieht das, dann muß es die in Frage stehende Sache sowohl in rechtlicher als auch in tatsächlicher Hinsicht selbst würdigen. Sein Urteil ergeht dann in erster und letzter Instanz. Das gleiche gilt, wenn es mit der Revision gegen das Urteil eines nachgeordneten Gerichts in einer bereits einmal weiterverwiesenen Sache befaßt wird. Eine Ausnahme bilden Schwurgerichtsurteile. Wegen des „caractère populaire" des "Cour d'Assises" muß hier in jedem Fall zurückverwiesen werden.

Das Verfahren vor dem Kassationsgerichtshof ist an sich öffentlich, doch wird in aller Regel nach Lage der Akten entschieden. Zum Tode Verurteilten ist grundsätzlich ein Pflichtverteidiger zu bestellen. Die Entscheidungen sind zu begründen und in einem eigens dafür vorgesehenen, aber bisher nie erschienenen Bulletin zu veröffentlichen?

Die Unzuträglichkeit der Personalunion zwischen „Cour d'Appel“ und „Tribunal Supérieur de Cassation" liegt auf der Hand. Dennoch hat sich die vielfach ausgesprochene Erwartung, es werde im Laufe der Zeit auch in Guinea zu einer institutionellen Trennung der beiden Gerichte kommen, bisher nicht erfüllt ${ }^{8}$.

Eingetroffen sind dagegen die skeptischen Voraussagen hinsichtlich des nach Erlangung der Unabhängigkeit, in Guinea wie in allen anderen afrikanischen Staaten auch, gegründeten Staatsgerichtshofs, des „Haute Cour de Justice“9. Dieses sollte nach der ursprünglichen Konzeption der Reformer, wonach für alle denkbaren Rechtsstreitigkeiten die ordentlichen Gerichte zuständig sein sollten, das einzige „Tribunal d'exception“ im Lande sein.

6 Ordonnance $\mathrm{Nr} .018$ v. 21. Februar 1959, J. O. R. G., Jahrgang 1959, Nr. 5, S. 125.

7 Kassationsprozeßordnung, Ordonnance Nr. 38 PG v. 9. Juli 1959.

8 Siehe hierzu M. Jeol La Réforme de la Justice en Afrique Noire, Paris 1963, S. 89 ff., mit zahlreichen Literaturhinweisen.

9 Ordonnance Nr. 29 v. 20. April 1959, J. O. R. G., Jahrgang 1959, Nr. 9, S. 282 ff. 
Unter dem Vorsitz des Präsidenten der Nationalversammlung und bestehend aus dem Justizminister, dem Innenminister, dem Verteidigungsminister und sechs vom Staatspräsidenten $\mathrm{zu}$ ernennenden Mitgliedern der Nationalversammlung erstreckt sich die Zuständigkeit dieses Staatsgerichtshofs „ratione materiae“ ganz allgemein $^{10}$ auf alle Verbrechen und Vergehen gegen die innere oder äußere Sicherheit des Staates, deren Tatbestände unter Strafbestimmungen des Strafgesetzbuches subsumiert werden können. Auch für die Strafzumessung ist grundsätzlich der "Code Pénal“ maßgeblich. Die durch diese beiden Vorschriften gebotene Respektierung der Rechtsordnung, und nicht, wie Jeol a. a. O. annimmt, die allzu generelle Kompetenzklausel, macht die Existenz des guineischen Staatsgerichtshofs zu einer Schimäre. Denn der progressistische Entwicklungsstaat, der „revolutionäre“ Staat, bedarf seiner Natur nach in Staatsschutzsachen einer Rechtsprechung, die an keinerlei Kautelen gebunden ist.

Der "Haute Cour de Justice“ ist daher seit vielen Jahren nicht mehr tätig geworden. An seine Stelle ist, als ein echtes Ausnahmegericht, das Revolutionstribunal („Tribunal Révolutionaire“) getreten. Schon das erste Komplott gegen das Regime Sékou Touré (Frühjahr 1960) kam nicht vor dem eigentlichen zuständigen Staatsgerichtshof, sondern vor einem durch Ordonnance ad hoc berufenen "Tribunal Populaire" zur Verhandlung11. Durch Gesetz Nr. 58/AN/62 wurde es in „Tribunal Revolutionnaire“ umbenannt. Bei späteren Anlässen ähnlicher Art entwickelte sich folgende Übung:

Das Politbüro der Einheitspartei P.D.G. ernennt ein sog. "Comité Révolutionnaire", das die Untersuchungen führt, die Anklage vorbereitet und die Strafanträge stellt ${ }^{12}$. Sodann wird ein außerordentlicher Nationaler Revolutionsrat einberufen und mit den Untersuchungsergebnissen und der Anklage bekanntgemacht. Die Partei erwirkt schließlich von der Nationalversammlung ein Gesetz, das den Nationalen Revolutionsrat ad hoc zum „Tribunal Révolutionnaire" erhebt ${ }^{13}$.

In dieser Eigenschaft verhandelt der Nationale Revolutionsrat bzw. die Nationalversammlung in öffentlicher Plenarsitzung über den Fall eines jeden Angeklagten, ohne daß diesem jedoch Gelegenheit zuteil würde, sich noch einmal zu rechtfertigen. Verhandlungsgegenstand sind die Tonbandaufnahmen der vor dem „Comité-Revolutionnaire“ abgelegten Geständnisse. Dann folgt, ohne vorherige geheime Beratung, die Verkündung der Urteile, gegen die es in aller Regel keine Rechtsmittel gibt, und mit denen das „Tribunal Révolutionnaire“ stets den Anträgen des „Comité Révolutionnaire" folgt oder gar über diese hinausgeht.

Trotz aller Bemühungen, diesem Vorgehen den Anschein eines ordentlichen Verfahrens zu geben, gibt es bislang weder ein Gesetz, das die Institution des „Tribunal Révolutionnaire" rechtlich fixiert, noch eine Verfahrensordnung, die verhindert, daß bei politischen Straftaten im wahrsten Sinne des Wortes „kurzer Prozeß“ gemacht wird. Die Ordonnance Nr. 023 v. 2. Mai 1960, durch die das oben

10 In den meisten übrigen frankophonen Staaten Westafrikas hat der Staatsgerichtshof darüber hinaus eine klare Kompetenz zur Ahndung von Amtsdelikten des Staatspräsidenten und der Mitglieder seines Kabinetts.

11 A. S. Touré, La Révolution Guinéenne et le Progrès Social, Bd. VI, Sonderausgabe, Conakry 1962, S. 39 ff.

$12 \mathrm{Im}$ Herbst 1965 setzte sich das "Comité Révolutionnaire" aus Léon Maka, Ismael Touré, Diakité Moussa, Camara Damantang und Mamouna Touré zusammen. Im Frühjahr 1969 waren es Diané Lansana, Ismael Touré, Mamadi Keita, Marcel Mathos, Noumandian Keita, Kaba Sékou, Sékou Sissoko, Karim Keita, Siaka Toure.

13 Gesetz v. 11. Mai 1969, siehe HOROYA-HEBDO Nr. 1664-18 vom 17.-23. Mai 1969, S. 18 ff. Anders jedoch im Januar 1971 bei der Aburteilung der Teilnehmer und „Komplizen“ des Invasionsversuches vom 22./23. November 1970. Hier konstituierten sich die Parteiversammlungen auf örtlicher, bezirklicher und 22./23. November 1970. Hier konstituierten sich die Parteiversammlungen auf örtlicher, bezirklicher und
regionaler Ebene als "Volksgerichte“, deren Strafanträge sodann die Nationalversammlung als Oberstes Revolutionsgericht zur" Grundlage der Strafzumessung machte. 
erwähnte "Tribunal Populaire" eingerichtet wurde, ist niemals veröffentlicht worden. Die Recht-, Schutz- und Ehrlosigkeit des politischen Gegners offenbart sich in diesem Zusammenhang für den progressistischen Entwicklungsstaat als eine schwere Hypothek, deren Gläubiger immer zahlreicher werden.

Abgesehen von der Gründung des Appellations-, des Kassations- und des Staatsgerichtshofs blieben institutionelle Reformen in den ersten zwei Jahren der Unabhängigkeit aus. Organisatorische Veränderungen ergaben sich zumeist aus einem aktuellen Bedürfnis oder aus dem Mangel an Kadern. Letzterem entsprang z. B. die Ausdehnung der Zuständigkeit des Einzelrichters ("Juge de Paix“) auf Arbeitssachen ${ }^{14}$ und auf die Vornahme untersuchungsrichterlicher Handlungen im Einvernehmen mit der Staatsanwaltschaft ${ }^{15}$.

Auf akute Bedürfnisse, nämlich die Unterdrückung der Diebstahls- und Wirtschaftskriminalität, ging die Ermächtigung der unteren Gerichte zurück, die in entsprechenden Ordonnancen angedrohten drakonischen Strafen, bis zur Todesstrafe bei Viehdiebstahl, zu verhängen ${ }^{16}$.

Erst die Ordonnance Nr. 047 v. 29. Dez. 196017 brachte eine grundsätzliche Reform, eine „Vereinheitlichung und Reorganisation der guineischen Justiz“. Sie verfügte vor allem die Auflösung aller Gerichte nach örtlichem Gewohnheitsrecht ${ }^{18}$ und unterwarf alle Bürger der Rechtsprechung durch die Gerichte des Gemeinen Rechts, ohne diesen allerdings die Anwendung materiellen Gewohnheitsrechts ausdrücklich zu verbieten. Lediglich das Verfahren wurde einheitlich der Zivilprozeßordnung unterstellt. Nach Art. 3 war in jeder der 29 Regionen eine "Justice de Paix à Compétence Etendue" einzurichten. Das ist bis auf Yomou geschehen. Dort allerdings, wo ein Tribunal I. Instanz seinen Sitz hat (Kankan, Labé, Kindia, Macenta), nimmt dieses zugleich die Zuständigkeiten der „Justice de Paix“ wahr. Lediglich in Conakry (Mafanco) amtiert neben einem Tribunal I. Instanz auch eine "Justice de Paix".

Die in der Ordonnance ebenfalls vorgesehenen "Justices de Paix à Compétence Civile Limitée" (Personenstandssachen, Zivilsachen bis 150000 F.G. Streitwert) sind bisher nicht eingerichtet worden. An ihrer Stelle wurde 1962 auf der Ebene der Parteikomitees und Parteisektionen eine Volksgerichtsbarkeit geschaffen ${ }^{19}$, mit der das Regime jedoch schlechte Erfahrungen gemacht hat.

Theoretisch amtiert danach in jedem Dorf und in jedem Stadtbezirk ein „Tribunal Populaire de Premier Degré und in jedem Arrondissement ein "Tribunal Populaire de Deuxième Degré“. Die Zuständigkeit dieser Gerichte, ursprünglich sehr viel weiter gefaßt, ist heute auf den Versuch der Schlichtung in ganz bestimmten Zivilsachen beschränkt. Den Vorsitz führt der jeweilige Parteisekretär. Sie verfahren nach örtlichem Gewohnheitsrecht.

Es sind also gegenwärtig unterhalb der Obergerichte 29 Gerichte Gemeinen Rechts (fünf Tribunale I. Instanz, 24 „Justices de Paix“) und eine unbestimmte Anzahl von Volksgerichten nach Gewohnheitsrecht tätig, gegliedert in fünf Gerichtsbe-

\footnotetext{
14 Dekret Nr. 149 PG-MJ v. 16. Juni 1959, J. O. R. G., Jahrgang 1959, Nr. 14, S. 442.

15 Dekret Nr. 128 MJ vom 15. Mai 1959, J. O. R. G., Jahrgang 1959, Nr. 11, S. 352.

16 Ordonnance Nr. 50 PG v. 15. Oktober 1959 in Verbindung mit Ordonnance Nr. $14 \mathrm{MJ}-\mathrm{PG}$ v. 14. Februar 1959, J. O. R. G., Jahrgang 1959, Nr. 24, S. 665 und Ordonnance Nr. 31 PG vom 8. August 1960 in Verbindung mit Ordonnance Nr. 009 PRG vom 29. Februar. 1960, J. O. R. G., Jahrgang 1960, Nr. 18, S. 294.

17 Abgedruckt in "Bulletin du Ministère de la Justice“ Nr. 1, Conakry 1965, S. $25 \mathrm{ff}$.

18 Nach A. P. A., "Coutumier Guinéen, gab es in Guinea 14 Gewohnheitsrechtfamilien (Soussou, Baga, Nalou, Landouma, Foulah, Ouassoulonké, Diakandé, Malinké, Dialonké, Kouranke, Toma, Guerze, Coniagui, Kissi).

19 Gesetz Nr. 58 AN/62 v. 14. April 1962, J. O. R. G., Jahrgang 1962, Nr. 15, S. 212.
} 
zirke, in denen jeweils der Staatsanwalt beim Tribunal I. Instanz die Dienstaufsicht führt ${ }^{20}$. Die Dienstaufsicht über die Volksgerichte obliegt jedoch - davon abweichend - der Einheitspartei.

Geplant ist, diese Struktur dahin zu verdichten, daß jede der vier Ministerdelegationen (überregionale Verwaltungseinheiten) über einen "Cour d'Appel“, jede Region über ein Tribunal I. Instanz und jedes Arrondissement über eine "Justice de Paix à Compétence Etendue" verfügt.

Bezeichnung, Organisation und Zuständigkeit der „Tribunaux de Première Instance" sowie der "Justices de Paix à Compétence Etendue" gehen auf das Recht der Kolonialmacht zurück. Es ist dies einer der allmählich seltener werdenden Fälle von Weitergeltung vorkonstitutioneller Vorschriften im Bereich des öffentlichen Rechts 21.

Die Tribunale I. Instanz sind in der Regel besetzt mit drei „magistrats“ (Präsident, Untersuchungsrichter, Staatsanwalt); die "Justices de Paix à Compétence Etendue“ dagegen sind nur mit Einzelrichtern ausgestattet. Ihre Zuständigkeiten sind im wesentlichen identisch: denn nach dem Willen des (frz.) Gesetzgebers bilden die im Gefolge der Justizreform von 1946 entstandenen "Justices de Paix" keine selbständige Instanz, sondern nur arbeitsteilige "Sektionen“ der Tribunale I. Instanz, gebildet, um den Grundsatz des „rapprocher la justice du justicable“ zu verwirklichen. Man vergleicht daher gern den afrikanischen "Juge de Paix“, der aus der Revolution von 1958 hervorgegangen ist, mit seinem aus der Revolution von 1789 hervorgegangenen französischen Pendant ${ }^{22}$.

Früher aus Mangel an Richtern oft ein Beamter der Kolonialverwaltung, ist der "Juge de Paix" im heutigen Guinea zumeist ein ehemaliger Justizangestellter mit großer Berufserfahrung. Da er seinen Sitz in zumeist abgelegenen Regionalhauptstädten hat, gilt er als dem Volke und seinem Rechtsempfinden besonders nahe. Die "Justice de Paix" wird daher rechtspolitisch als ein wichtiges Bindeglied zwischen Vergangenheit und Zukunft angesehen, insbesondere im Hinblick auf die eines Tages zwingend werdende Einbeziehung des "droit coutumier" in den Kreis des Gemeinen Rechts.

Daher ist auch die Schaffung der Volksgerichtsbarkeit viel eher ein Schritt in diese Richtung als der Versuch einer Nachahmung des Beispiels der sozialistischen Länder. Die letztere Annahme ${ }^{23}$ ist ein voreiliger Schluß aus der Bezeichnung „Tribunal Populaire“. Im Grunde nimmt die Volksgerichtsbarkeit nur den roten Faden afrikanischer Rechtstradition wieder auf, der durch die Auflösung der Gerichte nach örtlichem Gewohnheitsrecht vorübergehend fallengelassen worden war. Denn nach welchem Recht soll der Laienrichter der Volksgerichtsbarkeit urteilen, wenn nicht nach örtlichem Gewohnheitsrecht, dem einzigen, das er kennt?

Allerdings ist man bereits einen Schritt weiter. Man verzichtet auf die von einem große Teil der Bevölkerung als diskriminierend empfundene Unterscheidung zwi-

20 Gerichtsbezirk I: Conakry, Boké, Boffa, Dubréka, Fria, Arbeitsgericht Conakry; Gerichtsbezirk II: Kankan, Siguiri, Kérouané, Dabola, Dinguiraye, Kouroussa; Gerichtsbezirk III: Labé, Mamou, Pita, Dalaba, Mali, Tougué, Gaoual, Koundara; Gerichtsbezirk IV: Kindia, Telemelé, Forécariah;

Gerichtsbezirk V: Macenta, Beyla, Guéckédou, Kissidougou, Faranah, N'Zérékoré.

21 Frz. Dekret v. 19. Dezember 1957, J. O. R. F. v. 20. Dezember 1957.

22 M. Jeol a. a. O., S. 29. Mali), Paris 1965, S. 184. 
schen "droit commun" und „droit local“ und arbeitet im Stillen auf eine Rechtsvereinheitlichung hin, wobei natürlich außer Zweifel steht, daß Gemeines Recht Gewohnheitsrecht gegebenenfalls bricht.

Die in Guinea am 1. August 1968 eingeleitete "Sozialistische Kulturrevolution“ wird, wenn nicht alles täuscht, und soweit es die Einheit der Nation nicht gefährdet, auch zu einer Wiederbelebung, vielleicht gar zu einer Kodifizierung und Neuinterpretation der guineischen Gewohnheitsrechte führen. Denn das erklärte Ziel der Partei - „rendre la Justice toujours de plus en plus populaire, substituer à la rigueur parfois aveugle de la loi, le bon sens et la sagesse féconde de la masse" 24 - ist anders nicht $\mathrm{zu}$ erreichen.

Im Jahre 1962 war die Schaffung der „Tribunaux Populaires“ jedoch verfrüht. Das bereits zitierte Gesetz Nr. 58/AN/62 in Verbindung mit den Ausführungsvorschriften des Dekrets Nr. 304 vom 20. August 1962²5, eröffnete den Volksgerichten nämlich außer Zuständigkeiten in Zivilsachen (Geburt, Heirat, Tod, Schlichtungsversuch vor Ehescheidung) auch solche in Strafsachen (Auflauf, Ehebruch in flagranti, einfacher Diebstahl, Tötung fremder Tiere, Vernichtung von Ernten, Baumfrevel, Buschfeuer, Beleidigung, Wegnahme landwirtschaftlicher Geräte) und ermächtigte sie sogar, Haftstrafen bis zu 15 Tagen zu verhängen.

Darin sahen die örtlichen Machthaber, vielfach auch die alten Familien, die über einen der ihren an der örtlichen Staatsmacht teilhatten, eine willkommene Gelegenheit, ihre Herrschafts- und Willkürgelüste zu betätigen. Rasch häuften sich die Urteile, die auf Rechtsbruch, falschen Zeugenaussagen und sachfremden Erwägungen beruhten ${ }^{26}$. In der Bevölkerung machte sich Unruhe breit; die höheren Instanzen konnten die Flut der Beschwerden und Einsprüche nicht bewältigen. Daher sahen sich die Verantwortlichen schon ein Jahr später gezwungen, die $\mathrm{Zu}$ ständigkeit der Volksgerichte in Strafsachen bis auf weiteres auszusetzen und ihre Kompetenz in Zivilsachen auf bestimmte Personenstandssachen zu beschränken ${ }^{27}$.

Aber das reichte nicht aus. Es bedurfte weiterer Einschränkungen, um das mit der Schaffung der Volksgerichtsbarkeit angerichtete Urteil wiedergutzumachen.

So verblieb den Volksgerichten schließlich nur eine Rumpfzuständigkeit, eine befristete Schlichtungskompetenz, der sich der Bürger in allen Rechtsstreitigkeiten aus Eheschließung, Scheidung, böswilliger Verlassung, Fragen der Handlungsfähigkeit, Erbfolge, Schenkung und landwirtschaftlichen Besitzverhältnissen vorab zu unterwerfen hat ${ }^{28}$. Ferner wurde, um den durch das Gesetz Nr. 58/AN/62 ausgelösten Fraktionsbildungen innerhalb der örtlichen Parteileitungen einen Riegel vorzuschieben, der Exklusivcharakter der Volksgerichte aufgehoben. Sie setzten sich nun nicht mehr, wie ursprünglich vorgesehen ${ }^{29}$, jeweils nur aus fünf, sondern allen sechs Mitgliedern der örtlichen bzw. sektionalen Parteileitungen zusammen. Ortliche bzw. sektionale Parteileitung und örtliches bzw. sektionales Volksgericht sind seitdem dank völliger Personalunion miteinander identisch.

24 Präsidenten-Rundschreiben Nr. 56 PRG v. 18. Mai 1968.

25 J. O. R. G., Jahrgang 1962, Nr. 19, S. $163 \mathrm{ff}$.

26 Sékou Touré anläßlich der Wirtschaftskonferenz von Kissidougou, 14. Mai 1966, R. D. A.-Révue Nr. 7, Conakry, Juli 1966, S. $78 \mathrm{ff}$.

27 Präsidenten-Rundschreiben Nr. 016/PRG v. 2. Juli 1965.

28 Präsidenten-Rundschreiben Nr. 009/PRG v. 11. Februar 1964.

29 Nach dem Dekret Nr. 304 PRG v. 20. August 1962 setzte sich das „tribunal populaire du Ir degre aus dem Vorsitzenden der Parteiortsgruppe ("Comité de base") und vier ihrer Mitglieder, das "tribunal populaire du IIe degré aus dem Generalsekretär der Parteisektion und vier Mitgliedern des "Comité directeur" dieser Sektion zusammen. 
Erst wenn der Schlichtungsversuch in allen Instanzen (das „Bureau Fédéral“, die Bezirkleitung der Partei, bildet eine Art „tribunal populaire du IIIe degré") der Volksgerichtsbarkeit gescheitert ist, wird die Anrufung der Gerichte des Gemeinen Rechts zulässig. Mit Inkrafttreten dieser Regelung hatten die Tribunale I. Instanz und die "Justices du Paix" alle bei ihnen anhängigen Zivilsachen an die örtlichen Parteileitungen abzugeben ${ }^{30}$. Sékou Touré sparte nicht mit Ermahnungen. Zweck dieser Maßnahmen sei die Erhaltung des sozialen Friedens, die kontinuierliche Stärkung der Freundschaft und Solidarität unter den Angehörigen ein und derselben Partei, ein und derselben Nation. Um jeden Preis hätten die Parteileitungen ihre richterliche Funktion mit der "Macht der Argumente" und nicht umgekehrt mit den "Argumenten der Macht“ auszuüben. Parteilichkeit und Einschüchterung seien absolut unzulässig.

Kaum waren diese Mißbräuche einigermaßen unterbunden, erwies sich die Volksgerichtsbarkeit als umständlich und langsam. Die Regierung sah sich daher gezwungen, das Schlichtungsverfahren im Interesse einer "Justice rapide" auf die Dauer von höchstens drei Monaten zu befristen, so daß nunmehr nach erfolglosem Ablauf dieser Frist, ohne Rücksicht auf den Stand des Schlichtungsverfahrens, die Gerichte des Gemeinen Rechts angerufen werden können ${ }^{31}$.

Damit ist ein halbwegs befriedigender Zustand geschaffen. Ob er die im Rundschreiben Nr. 016 PRG verordnete „adaption progressive“ der Volksgerichtsbarkeit in dem Sinne ermöglicht, daß ihre Zuständigkeit allmählich wieder erweitert werden kann, muß abgewartet werden. In jedem Falle gilt nach einem Rundschreiben Sékou Tourés vom 3. August 1964 die schiedliche Versöhnung streitender Parteien nach afrikanischer Tradition, die sich darin mit dem Islam treffe, als Eckstein eines neuen Verfahrensrechts.

Ausnahmegerichtsbarkeiten neben dem Staatsgerichtshof (später: Tribunal Révolutionnaire), sollten - wie schon erwähnt - in Guinea nach der ursprünglichen Absicht der P.D.G.-Führung nicht geschaffen werden. Insbesondere eine spezielle Militärgerichtsbarkeit schien der Partei unvereinbar mit ihrer "globalen Konzeption" von der Nation und den Organen der Staatsmacht. Aus demselben Grunde sträubte sie sich lange gegen eine Verwaltungsgerichtsbarkeit, die nach ihrer Auffassung nur Anlaß zur Entwicklung von Antagonismen, ja zum Aufleben der Diskussion um die Gewaltenteilung, geben konnte ${ }^{32}$.

Militärstrafsachen und Verwaltungsstreitigkeiten gehörten daher in den ersten Jahren der Republik in die Zuständigkeit der Tribunale I. Instanz. Aber die Verhältnisse waren stärker. Schon im Juli 1963 deutete ein Rundschreiben des Staatspräsidenten einen Sinneswandel $\mathrm{an}^{33}$. Es ging um die Verfolgung straffällig gewordener Militärangehöriger, deren Vorgesetzte immer mehr dazu übergingen, sie dem Zugriff der Justiz zu entziehen.

"Jusqu’à nouvel ordre" ordnete der Präsident folgendes an: Disziplinwidrigkeiten und im Kasernenbereich begangene Bagatelldelikte sind disziplinarisch, alle anderen Übertretungen, Vergehen und Verbrechen aber von den ordentlichen Gerichten zu ahnden.

30 Präsidenten-Rundschreiben Nr. 009/PRG v. 11. Februar 1964.

31 Präsidenten-Rundschreiben Nr. 009/PRG v. 11. Februar 1964.

32 Generalstaatsanwalt Fadiala Keita vor der Nationalversammlung, HOROYA Nr. 326 v. 12. November 1963.

33 Präsidenten-Rundschreiben Nr. 016/PRG v. 2. Juli 1964. 
Als erste Ausnahmegerichte wurden 1964/65 - später als in den übrigen Nachfolgestaaten des französischen Kolonialreichs - ein Verwaltungsgericht („Tribunal Administratif“) und ein Konfliktgericht („Tribunal des conflits“) ins Leben gerufen ${ }^{34}$. Sie unterstehen nicht der Dienstaufsicht des Justizministeriums, sondern der des Präsidialamtes der Republik.

Das Verwaltungsgericht ${ }^{35}$ setzt sich aus einem Berufsrichter als Präsidenten und vier hohen Staatsfunktionären als Beisitzern zusammen. Als Generalsekretär fungiert ein Regierungskommissar. Das Verwaltungsgericht ist ausschließlich zuständig für alle Rechtsstreitigkeiten administrativer Natur aus Verwaltungs- oder Hoheitsakten bzw. aus der Durchführung öffentlicher Aufgaben. Die Zuständigkeit des Verwaltungsgerichts erstreckt sich aber ausdrücklich nicht auf die Handlungen des Staatspräsidenten.

Das Konfliktgericht hat den Justizminister (Staatssekretär) zum Präsidenten sowie zwei Berufsrichter und zwei Staatsfunktionäre zu Beisitzern. Wie die Richter am Verwaltungsgericht werden auch sie durch Dekret ernannt.

In die Zuständigkeit des Konfliktgerichts fallen sämtliche positiven und negativen Kompetenzkonflikte sowie die Entscheidungskonflikte zwischen dem Verwaltungsgericht und den ordentlichen Gerichten. Wie das "Tribunal Administratif“ wird das "Tribunal des conflits" nur auf Antrag tätig. Auch hier werden die Interessen der Republik durch einen Regierungskommissar wahrgenommen. Gegen die Entscheidungen beider Gerichte gibt es keine Berufung, gegen die des Verwaltungsgerichts kann jedoch Einspruch erhoben oder Revision bzw. Berichtigung beantragt werden.

Als nächstes Ausnahmegericht wurde überraschend ein Militärtribunal („Tribunal Militaire") errichtet ${ }^{36}$. Es hat seinen Sitz in Conakry und untersteht der Dienstaufsicht des Verteidigungsressorts. Die Zusammensetzung ist originell: als Präsident fungiert der Staatssekretär für Verteidigung, als Beisitzer der Generalstabschef sowie ein Oberst, ein Bataillonskommandeur, ein Hauptmann, ein Leutnant, ein Unteroffizier und ein Soldat. Das Gericht ist zuständig für alle von Soldaten und Gleichgestellten im Dienst verübten Vergehen und Verbrechen, sei es im Inland oder Ausland, insbesondere Befehlsverweigerung und wehrschädigendes Verhalten, aber auch alle Straftatbestände des Strafgesetzbuches. Die Sitzungen des Gerichts sind nicht öffentlich, gegen seine Urteile gibt es keine Rechtsmittel. Rechtskraft erlangen sie jedoch erst nach Billigung durch den Staatspräsidenten.

Ein echtes Sondergericht ist das „Tribunal Spécial pour les infractions économiques" ${ }^{37}$. Es ist als Schnellgericht zur Bekämpfung der immer mehr um sich greifenden Wirtschaftskriminalität bestimmt. Seine Urteile ergehen binnen 8 Tagen nach Eingang der Anzeige. Seine Zuständigkeit umfaßt alle Zolldelikte und Devisenvergehen, die Unterdrückung, Fälschung oder mißbräuchliche Benutzung von Rechnungen und Frachtpapieren der Staatsbetriebe, die Hortung von Waren und die direkte oder indirekte Störung der Aufkaufaktionen für landwirtschaftliche Erzeugnisse, soweit ihre Wiedergutmachung Kosten von 100000 F.G. oder mehr

\footnotetext{
34 Dekret Nr. 90 PRG v. 5. Adril 1965, I. O. R. G. Jahrgang 1965, Nr. 9, S. 98 ff., Dekret Nr. 310 PRG v. 23. August 1968, J. O. R. G. Jahrgang 1968, Nr. 19, S. 206

35 Was hier Tribunal Administratif heißt, wird in Kamerun "Tribunal d'Etat", in Togo „Conseil du Contentieux " genannt. Guinea folgt insoweit der französischen Tradition.

36 Dekret Nr. 69 PRG v. 19. Februar 1966, J. O. R. G. Jahrgang 1966, Nr. 6, S. 82.

37 Gesetz Nr. 50/AN/66, J. O. R. G. Jahrgang 1966, Nr. 6, S. 82 in Verbindung mit Gesetz Nr. 72/AN/67, J. O. R. G. Jahrgang 1967, Nr. 13, S. 156.
} 
verursachen würde. Das Gesetz beauftragt mit der Aufspürung solcher Delikte außer Zoll, Gendarmerie und Wirtschaftspolizei übrigens auch die staatliche Jugendorganisation J.-R.D.A., was bereits zu mancher „Hexenjagd“ geführt hat.

Gegen die Urteile des „Tribunal pour les infractions économiques“ gibt es nur die Revision. Durch Dekret Nr. 268 PRG vom 22. Juli 1968 wurde die Zusammensetzung des Gerichts in beträchtlicher Abweichung von den Vorschriften des Gesetzes Nr. 50/AN/66 wie folgt festgesetzt: der Staatssekretär des Inneren führt den Vorsitz, zwei ZK-Mitglieder und der Kommandeur der Gendarmerie fungieren als Beisitzer ${ }^{38}$.

Durch die Schaffung dieses Gerichts wird der ordentlichen Gerichtsbarkeit eine wichtige - wenn nicht die wichtigste - Gruppe von Verstößen gegen die Rechtsordnung entzogen. Sie können auf diese Weise nicht nur rascher, sondern auch härter geahndet werden.

Das bislang jüngste Organ der guineischen Rechtspflege, wenngleich kein Gericht, ist der Rechnungshof (Cour des Comptes). Auch mit dieser Gründung folgt Guinea dem Beispiel Frankreichs und nicht dem seiner afrikanischen Nachbarn, die den "Contentieux financier" in die Zuständigkeit besonderer Senate ihrer Staatsgerichtshöfe gestellt haben ${ }^{39}$.

Der Rechnungshof ist keine Gerichtsbarkeit des Gemeinen Rechts. Er prüft die "Comptes de la Nation" und wacht über ein ordentliches Haushaltsgebaren. Er setzt sich aus fünf Kammern zusammen, von denen jede für die Prüfung einer bestimmten Gruppe von Haushalten zuständig ist. Im übrigen bestimmen sich die Zuständigkeiten des Rechnungshofs nach den einschlägigen Haushaltsvorschriften ${ }^{40}$.

Die Einrichtung des Rechnungshofs war als flankierende Maßnahme zur Schaffung des Staatssekretariats für Finanzkontrolle gedacht. Sie erinnert damit an das Kardinalproblem der Verwaltung im progressistischen Entwicklungsstaat: die Erzwingung einer sparsamen, redlichen und sachgerechten Verwendung der knappen öffentlichen Mittel ${ }^{41}$.

Eigentlich mehr der Vollständigkeit halber sei in diesem Zusammenhang noch eine Gerichtsbarkeit erwähnt, die, von der Kolonialmacht in besonderem Maße gefördert $^{42}$, ein Relikt einer bürgerlichen Gesellschaftsordnung ist und im progressistischen Entwicklungsstaat nur noch im Verborgenen blüht: die Arbeitsgerichtsbarkeit.

Von den beiden Arbeitsgerichten, die es 1958 in Guinea gab (Conakry und Kankan) ist nur das in Conakry erhalten geblieben. Seine Zuständigkeit ist auf das Gebiet der Hauptstadt beschränkt. In allen anderen Verwaltungsregionen gehören die arbeits- und tarifrechtlichen Streitigkeiten in die Zuständigkeit der ordentlichen Gerichte, ohne daß ein Instanzenzug zum „Tribunal du Travail“ in Conakry gegeben wäre.

\footnotetext{
38 Das Gesetz Nr. 50/AN/66 hatte als Vorsitzenden den Minister für Außenhandel, als Beisitzer die Staatssekretäre für Inneres und Justiz sowie den Präsidenten des Cour d'Appel vorgesehen.

39 M. Jeol a. a. O., S. $82 \mathrm{ff}$. 15. September 1967, J. O. R. G. Jahrgang 1967, Nr. 20, S. 253.

41 Siehe hierzu: "La Réforme financière" in A. S. Touré, Le Pouvoir Populaire, Bd. XVI (2), Conakry 1968, S. $197 \mathrm{ff}$." ferner "L'Etat Révolutionnaire“ in A. S. Touré, Vingtième Anniversaire et Huitième Congrès, Bd. ẌVI (1), Conakry 1967, S. 83 Mitte ff.

42 P.-F. Gonidec, M. Kirsch, Droit du travail des territoires d'outre-mer, Paris 1958.
} 


\section{b) Die Stellung der Richter und Anwälte}

Die Richter sind Staatsfunktionäre. Das Prinzip der Unabhängigkeit des Richters ist ebenso wie das Prinzip der Gewaltenteilung mit dem Wesen des revolutionären Staates unvereinbar. Es gilt als „notion chère à certains nostalgiques du régime colonial" und ist damit disqualifiziert. Im Gegensatz $\mathrm{zu}$ ihren Kollegen in den anderen frankophonen Staaten Schwarzafrikas genießen die guineischen Richter daher auch nicht den Vorzug eines besonderen Richtergesetzes („Statut de la Magistrature“), sondern unterliegen dem allgemeinen Beamtenrecht („Statut Particulier des Divers Cadres Uniques“43), in dessen Rahmen sie zusammen mit den Anwälten, Notaren und Gerichtsvollziehern den "Cadre unique de la Justice et du Travail“ bilden (Art. 121 ff.). Der Kadermangel ist außerordentlich groß. Die Berufung von Funktionären der allgemeinen Verwaltung oder auch der Polizei in Funktionen der Justiz ist daher an der Tagesordnung ${ }^{44}$.

Der Freiberuflichkeit der Rechtsanwälte, Notare und Gerichtsvollzieher war bereits mit Wirkung vom 1. April 1960 durch die sog. "fonctionnarisation“ dieses Berufsstandes ein Ende gemacht worden ${ }^{45}$. Sie sind seitdem wie die Richter festbesoldete Staatsfunktionäre, d. h. Beamte ohne beamtenrechtliche Privilegien. Die Annahme von Honoraren ist ihnen bei Strafe verboten. Schon 1959 hatte das Regime alle in Guinea ansässigen Rechtsanwälte, Notare und Gerichtsvollzieher, soweit sie keine Guineer waren, vor die Wahl gestellt, entweder die guineische Staatsangehörigkeit anzunehmen oder auf die Ausübung ihres Berufes zu verzichten ${ }^{46}$. Nach außen wurde die Verbeamtung der Anwälte etc. mit dem Erfordernis begründet, dem 1959 eingeführten Prinzip der Unentgeltlichkeit der Rechtspflege zur vollen Geltung $\mathrm{zu}$ verhelfen. Dahinter standen jedoch gesellschaftspolitische Motivationen und - nicht zuletzt - wiederum der Kadermangel. Denn die nach dem Exodus der Franzosen in Guinea verbliebenen Anwälte waren an den Fingern einer Hand abzuzählen. Das ganze schöne Prinzip der Unentgeltlichkeit war nutzlos, wenn der Staat nicht imstande war, den vielfältigen Rechtsbeistand sicherzustellen, der landauf, landab gebraucht wurde. Daher verfiel das Regime 1964 auf den Ausweg, ein Kollegium von Funktionären der allgemeinen Verwaltung („Collège d'Agents de l'Administration Générale“) zu berufen, dessen Aufgabe es ist, „conjointement avec des Avocats-Défenseurs en service d'assurer la défense des intérêts des plaideurs" 47 .

Zusammen mit der Vereinheitlichung des Rechtsprechungapparats mittels Auflösung der „Tribunaux coutumiers" und der Einführung des Prinzips „Humanité Gratuité - Rapidité" bildet die Verbeamtung der Richter und Anwälte den Kern der nachkolonialen Justizreform.

Diese wird jedoch nicht nur aus regime- und ideologieadäquaten Erwägungen gespeist, sondern auch aus dem Trauma der Erinnerung an eine Kolonialjustiz vornehmlich repressiven Charakters, aus welcher der revolutionäre Staat eine Justiz vornehmlich edukativen Charakters zu entwickeln sich vorgenommen hat.

43 Dekret Nr. 146 PRG v. 4. Juni 1965.

44 Siehe z. B. Dekret Nr. 203 PRG v. 17. Juni 1967, J. O. R. G. Jahrgang 1967, Nr. 13, S. 158.

45 Dekret Nr. 67 PG v. 3. März 1960, J. O. R. G. Jahrgang 1960, Nr. 10, S. $174 \mathrm{ff}$.

46 Ordonnance Nr. 25 PG v. 28. März 1959, J. O. R. G. Jahrgang 1959, Nr. 8, S. 236

47 Dekret Nr. 271 PRG v. 1. Juli 1964, abgedruckt in Bulletin du Ministère de la Justice Nr. 1, Conakry 1965, S. 20. 
Schon vor dem V. Parteikongreß hatte Sékou Touré (1959) es als die Aufgabe seiner Partei bezeichnet „de transformer, de rénover, de reconvertir aussi bien la matiére que l'esprit de la Justice" 48 .

Wurde die Justiz des Kolonialregimes als „Unterdrückungs- und Beherrschungsinstrument in den Händen der Kolonialmacht zur Perpetuierung ihrer Herrschaft" empfunden, so soll sie jetzt ein "Faktor des sozialen Ausgleichs" sein, gereinigt von allen „aspects mystificateurs et intimidants“. Die Furcht des Volkes vor dem Richter soll abgebaut werden: „On ne doit pas avoir peur d'un juge. Au contraire, on doit aimer un juge." Das Volk soll lernen, im Richter den getreuen Ausdruck des Willens aller billig und gerecht Denkenden zu sehen, den sichersten Vertrauten eines jeden Bürgers, den absolut integren Mitbürger, der über den Leidenschaften, der Ungleichheit und den Lastern der anderen steht. Der Richter soll nicht länger eine Zielscheibe des Mißtrauens, des Unverständnisses oder gar des Hasses sein. Die Partei will ihn „zum Bruder, Freund und Kameraden eines jeden Bürgers“ machen ${ }^{49}$.

Daß der Unterschied zwischen Ideal und Wirklichkeit hier besonders kraß zutagetritt, bedarf kaum der besonderen Erwähnung.

Das Regime hat, besonders in den Jahren 1963/64, immer wieder versucht, seine Vorstellungen vom Beruf des Richters und des Anwalts in ihm gemäße Definitionen zu fassen.

Von grundlegender Bedeutung für die Stellung der Richter und Staatsanwälte ist das Rundschreiben des Präsidenten der Republik v. 2. Juli 196350. Bis dahin hat offenbar in vielfacher Hinsicht Unklarheit geherrscht. Ein für allemal stellt das Rundschreiben daher klar, daß

1. weder die Justiz „une chose à part“ noch die Richterschaft „un corps indépendant des autres organes de l'Etat" bildet;

2. die Aufgaben des Richters und die des Staatsanwalts als absolut „komplementär" aufzufassen sind und daher

3. jede Kontroverse, jeder Antagonismus zwischen Richter und Staatsanwalt sowie zwischen Justiz und allgemeiner Verwaltung „wegen der schädlichen Rückwirkungen auf die Interessen des Volkes" $\mathrm{zu}$ vermeiden ist ${ }^{51}$.

Die Richter haben es in den ersten Jahren der Republik verstanden, sich der Neigung der Staatsanwälte und der allgemeinen Verwaltung zur Beugung des Rechts mit einem gewissen Erfolg zu widersetzen. Das zitierte Rundschreiben hält es für nötig, die Richter darauf hinzuweisen, daß

1. im Strafprozeß der Staatsanwalt ebenso wie der Verurteilte das Rechtsmittel der Berufung hat;

2. der Staatsanwalt (und nicht der Richter) den Strafvollzug überwacht;

48 S. Touré, Expérience Guinéenne et Unité Africaine, Paris 1962, S. $517 \mathrm{ff}$.

49 Ebenda, S. 519.

50 Präsidenten-Rundschreiben Nr. 016 PRG v. 2. Juli 1963, abgedruckt in Bulletin du Ministère de la Justice Nr. 1, Conakry 1965, S. $40 \mathrm{ff}$.

51 Die Justiz hat sich mit den Behörden der allgemeinen Verwaltung vor jeder richterlichen Entscheidung ins Benehmen zu setzen, die „une répercusion fàcheuse sur le climat politique ou l'opinion publique“ haben könnte; andererseits soll aber die allgemeine Verwaltung jeden Einmischungsversuch in schwebende haben könnte; andererseits soll aber die allgemeine Verwaltung jeden Einmischungsversuch in schwebende
Verfahren unterlassen (ebenda), Gemäß Rundschreiben Nr. 015 PRG v. 19. April 1960 ist zur. StrafVerfahren unterlassen (ebenda), Gemäß Rundschreiben Nr. 015 PRG v. 19. April 1960 ist zur Straf-
verfolgung von Gouverneuren, Kreiskommandanten, Behördenleitern sowie Mitgliedern der Regionalen Volksvertretungen und Parteileitungen die vorherige Genehmigung des Staatschefs erforderlich. 
3. der Staatsanwalt auch bestimmte Zivilsachen (Scheidung, Personenstandsbeurkundungen, Staatsangehörigkeitssachen) an sich zu ziehen berechtigt ist;

4. die Weisungsbefugnis gegenüber den Hilfsbeamten der Staatsanwaltschaft ${ }^{52}$ bei dieser und nicht beim Richter liegt;

5. die Strafverfolgung allein Sache des Staatsanwalts und

6. jedes ohne Mitwirkung des Staatsanwalts zustandegekommene Urteil in Strafsachen nichtig ist.

Eine schwere politische Rüge handelten sich die Richter mit ihrem Verhalten gegenüber Störungen der öffentlichen Ordnung ein. Ersuchen der Behörden der allgemeinen Verwaltung um richterliche Maßnahmen (Haftbefehl etc.) hatten sie lange Zeit mit der Begründung abgelehnt, die inkriminierten Tatbestände seien durch kein Gesetz mit Strafe bedroht.

Das Justizministerium unterstellte ihnen daraufhin mangelnde Gesetzeskenntnis und repetiert seitdem auf regelmäßigen Richterkonferenzen die in Guinea am häufigsten vorkommenden Verstöße gegen die Vorschriften zum Schutz der öffentlichen Ordnung. Eine Aufzählung aus dem Jahre 1965 ist aufschlußreich; der Reihe nach sind es: Verunglimpfung der Staatsgewalt, Widerstand gegen die Staatsgewalt, Aufruhr, Amtsanmaßung, Gruppenbildung zur gemeinsamen Verübung von Verbrechen, falsche Anschuldigung zwecks Herbeiführung strafrechtlicher oder disziplinarrechtlicher Verfolgung53.

Periodischer Kritik von seiten der Staatsführung sind die Richter auch wegen ihrer Verstöße gegen das Gebot der "Justice rapide“ ausgesetzt. Insbesondere der Zivilprozeß wird oft in unerträglicher Weise verschleppt. Die Gründe dafür liegen aber meist weniger in der Person des mit der Sache befaßten Richters als vielmehr im Problem des Kadermangels. Die Volksgerichtsbarkeit ist wider die Absicht der Reformer nicht in der Lage, die ordentlichen Gerichte wirksam zu entlasten ${ }^{54}$.

Allerdings ruft die Verschleppung von Zivilsachen die Staatsmacht erst dann auf den Plan, wenn sie eine Gefahr für „das Gleichgewicht, die Harmonie, die Sicherheit und den Frieden im Schoße der guineischen Gesellschaft" zu werden droht.

Nur in diesem engverstandenen Sinne ist der Richter im progressistischen Entwicklungsstaat ein „facteur d'équilibre social“. Nicht der Schutz des Rechts, sondern der Gesellschaftsordnung, ist seine Hauptaufgabe: „Wenn es die Aufgabe des Richters sein soll, das Recht zu interpretieren, dann hat diese Interpretation in Guinea im Sinne einer ,adaptation rigoureusement conforme aux intérêts de la Révolution' zu erfolgen ${ }^{55}$."

Dementsprechend wurde auch Stellung und Aufgabe des Rechtsanwalts „in der guineischen Revolution" definiert ${ }^{56}$. Danach ist er ein "Gehilfe der Justiz“, der nicht nur die Interessen seines Klienten, sondern auch die des Prozeßgegners und „surtout de la Sociétéc wahrzunehmen hat. Als Staatsfunktionär (s. o.) untersteht der Anwalt dem Weisungsrecht des Generalstaatsanwalts und muß sich jede Kritik an dem Staat, dem er dient, versagen.

52 Dies sind in Guinea die Gouverneure, die Kreiskommandanten sowie die Gendamerie- und Polizeioffiziere.

53 Conférence des Cadres de la Justice, Bulletin du Ministère de la Justice Nr. 1, Conakry 1965, S. $63 \mathrm{ff}$.

54 S. Präsidenten-Rundschreiben Nr. 56/PRG v. 15. Juli 1964, abgedruckt in Bulletin du Ministère de la Justice Nr. 1, Conakry 1965, S. $45 \mathrm{ff}$

55 Conférence des Cadres de la Justice, Bulletin du Ministère de la Justice Nr. 1, Conakry 1965, S. $50 \mathrm{ff}$.

56 Zirkularnote des Justizministers v. 3. August 1964, abgedruckt in Bulletin du Ministère de la Justice Nr. 1, Conakry 1965, S. $22 \mathrm{ff}$. 
Sein Plädoyer im Strafprozeß ist grundsätzlich mündlich. Es darf nicht darauf ausgehen, den Staatsanwalt zu widerlegen, sondern muß bemüht sein, diesen $z u$ ergänzen, zu vervollständigen („doit avoir un sens complémentaire et non antagoniste"). Soweit er schon im Untersuchungsstadium hinzugezogen wird, muß er bedenken, daß er ein "auxiliaire de la Justice“ ist und als solcher zur Wahrheitsfindung beizutragen hat. Vor allem darf er den Prozeß der Wahrheitsfindung nicht durch "Advokatentricks" erschweren.

In Zivil- und Handelssachen darf es nicht das Ziel des Anwalts sein, durch „Überrumpelung des Richters" eine für seinen Mandanten günstige Entscheidung herbeizuführen. Vielmehr hat er sich um eine vollständige Klärung des Falles zu bemühen und zu diesem Zweck alle seine Anträge der gegnerischen Partei oder ihrem Rechtsbeistand sowie dem Gericht in schriftlicher Form und in angemessener Frist zuzustellen, um diesen eine Stellungnahme bzw. eine Entscheidung „en toute connaissance de cause" zu ermöglichen. Höchstes Ziel des Anwalts im Zivilprozeß hat nach afrikanischer Tradition die Versöhnung zu sein ${ }^{57}$.

Sieht man von dieser Einschränkung ab, deren Wert über den einer Reminiszenz bislang kaum hinausgeht, so wird nirgend die Nähe des guineischen Rechtsdenkens zur Rechtsauffassung in den sozialistischen Staaten Osteuropas offenbarer. Sékou Tourés Wort von der Justiz, die künftig nicht mehr als unabhängig von anderen Lebensäußerungen der Staatsmacht, nicht mehr als isoliert von den wirtschaftlichen und politischen Bedingungen des Landes gesehen werden dürfte ${ }^{58}$, orientiert sich unverkennbar am sozialistischen Vorbild. Rechtsanwendung und Rechtsprechung sind damit auch in Guinea „ein Teil gesellschaftlicher Praxis und folglich ein Mittel bewußter politisch-sozialer Gestaltung und Umgestaltung" ${ }^{59}$. Die Prinzipien der „sozialistischen Gesetzlichkeit“ und der „Parteilichkeit der Rechtspflege" regieren auch hier.

\section{Die Rechtsreformen}

\section{a) Die gesellschaftspolitischen Zielsetzungen}

Mit der oben beschriebenen Vorstellung von den Aufgaben der Justiz im progressistischen Entwicklungsstaat korrespondiert die Vorstellung von der nachkolonialen Gesetzgebung als einem wichtigen Hilfsmittel zur Herbeiführung des angestrebten sozialen und kulturellen Wandels. Unter den verschiedenen Möglichkeiten nachkolonialer Rechtspolitik ${ }^{60}$ hat sich das Guinea Sékou Tourés für eine Revolutionierung des überkommenen Rechtssystems entschieden.

Diese Entscheidung wurde zunächst vorwiegend nationalistisch motiviert. Bereits 1959 (V. Parteitag) forderte Sékou Touré die Schaffung eines originär guineischen Rechts, „conforme à nos propres réalités, inspiré par notre milieu humain et social“ (nicht länger durch das französische), „exprimant . . . la valeur de notre civilisation" (nicht länger der französischen). Schon damals fügte Sékou Touré hin$\mathrm{zu}$, dieses neu zu schaffende Recht sei nach den Zielen der Revolution zu modellieren $^{61}$.

57 „Dans nos sociétés africaines, l'objectif fondamental dans tout procès est de rétablir la concorde et "'harmonie dans la cité" (ebenda).

58 „La Réforme judiciaire“ in A. S. Touré, Expérience Guinéenne et Unité Africaine, Paris 1962, S. 517.

59 Ernst-Wolfgang Böckenförde, Die Rechtsauffassung im kommunistischen Staat, München 1967, S. 66 ff.

60 A. Schiller, Les Aspects juridiques du Développement Economique, Paris 1966.

61 A. S. Touré, L'Expérience Guinéenne et Unité Africaine, Paris 1962, S. 518 ff. 
Das rechtspolitische Ideal der guineischen Revolution formuliert Touré wie folgt: „Reconvertir le Droit, conformément aux intérêts du peuple, c'est socialiser la legislation . . . , afin que la justice s'identifie au Droit, le Droit à la Loi, la Loi à l'intérêt du Peuple et l'intérêt du Peuple à celui de la Nation"62."

Ausgehend von der Kritik am Eigentumsbegriff des bürgerlichen Rechts setzt er (ebenda) der guineischen Gesetzgebung das Ziel, den revolutionären Prozeß in der Welt durch Liquidierung der sozialen Unterschiede, durch Beseitigung der bestehenden gesellschaftlichen Ausbeutungs- und Unterdrückungsverhältnisse beschleunigen zu helfen.

Doch nirgends hat die Revolution so geringe Erfolge zu verzeichnen wie auf dem Felde der Rechtspolitik. Lediglich die Domänen des öffentlichen Rechts, einschließlich des Strafrechts, konnten bisher einer gewissen Neuordnung zugeführt werden. Die gesellschaftspolitisch viel entscheidendere Aufgabe einer Neuordnung des Zivil- und Handelsrechts sowie die Vereinheitlichung von Gemeinem und Gewohnheitsrecht, blieb, außer im Bereich des Ehe- und Bodenrechts, im Ansatz stecken.

Geht man davon aus, daß die Entwicklung progressistischer Staatswesen in drei Etappen verläuft $\mathrm{t}^{63}$, dann befindet sich das Regime Tourés nach über zehn Jahren Unabhängigkeit noch immer in der ersten, nämlich der seiner Errichtung und Festigung. Die Rolle des Klassenfeindes spielt die kleinbürgerliche Konterrevolution. Nach wie vor hat die Staatsgewalt hauptsächlich repressive Aufgaben: „... procéder à l'assainissement de la société en extirpant les malfaiteurs, en premier lieu du secteur public et semi-public par la lutte sans merci contre les auteurs de détournements de deniers et biens publics..." (Moussa Diakité a. a. 0.) Die Neuregelung weiter Bereiche des sozialen Lebens muß sie daher bis auf weiteres ausklammern, auch wenn dadurch Tatbestände perpetuiert werden, die, wie der Fortbestand indigener Rechtsaltertümer und Rechtszersplitterung auf den Gebieten des Schuldrechts, des Sachenrechts und des Erbrechts, ausgesprochen konterrevolutionär wirken.

Zwar wird von seiten des Regimes gelegentlich auf die Notwendigkeit hingewiesen, die indigenen Gewohnheitsrechte wenigstens zu kodifizieren ${ }^{64}$ und - in fernerer Zeit - auch zu vereinheitlichen. Doch der nationale Burgfriede („la paix dans la cité") geht vor. Er läßt es geraten erscheinen, die Autonomie der guineischen Stämme in diesem letzten Reservat traditioneller Regelungsfreiheit vorerst nicht anzutasten. Der bald nach der Unabhängigkeit unternommene Versuch, die indigenen Gewohnheitsrechte durch Auflösung der „Tribunaux Coutumiers“ einfach obsolet zu machen, ist gescheitert. Der Druck der Bevölkerung war so stark, daß diese Gerichtsbarkeit als sog. Volksgerichtsbarkeit 1962 wieder zugelassen werden mußte und so - wenn auch nur in sehr engem Rahmen - Zeugnis ablegen kann für die nur oberflächlich gelöste Problematik des "nation-building“ in den afrikanischen Staaten südlich der Sahara. Sie alle stehen vor der Frage, wie die beiden widersprüchlichen Gebote des Augenblicks, das der Modernisierung und das der Afrikanisierung, miteinander zu vereinbaren seien. Im Guinea Sékou Tourés wird, das läßt sich heute schon mit Bestimmtheit sagen, die revolutionäre

62 A. S. Touré, L'Afrique en Marche, Schweizer Neuauflage 1967, S. $364 \mathrm{ff}$.

63 Errichtung und Festigung des Regimes, Übergang von der nationalen zur Volksdemokratie, umfassender

64 I. N. R. D. G., Coutomier Guinéen (hektogr. Nachdruck eines Dokuments der französischen Kolonialverwaltung, Conakry 1968). 
Forderung nach Modernisierung über die eher konservative Forderung nach Afrikanisierung den Sieg davontragen. Das künftige Antlitz der guineischen Rechtsordnung wird, wenn das Regime Sékou Touré Bestand haben sollte, nicht traditionelle, sondern revolutionäre Züge tragen, „inspirée de nos principes politiques,

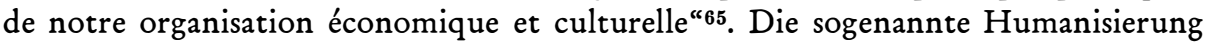
der Ehe und die Sozialisierung von Grund und Boden legen dafür Zeugnis ab.

\section{b) Das Eherecht}

Als rechtloseste Bevölkerungsschicht unter dem alten System aus Kolonialismus und Traditionalismus erschienen Sékou Touré die Frauen. Er hielt sie für die erbarmungswürdigsten Opfer der Ausbeutung des Menschen durch den Menschen und glaubte, daß sie in einem revolutionären Wandlungsprozeß nichts zu verlieren, aber alles zu gewinnen hätten, weshalb sie am ehesten bereit sein würden, für die Herbeiführung dieses Wandels zu kämpfen. Der soziale Anlaß, die Verwirklichung der Gleichberechtigung zwischen den Geschlechtern, barg politische Dynamik. Die Frauenemanzipation konnte Wasser sein auf die Mühlen der Revolution. Im wesentlichen ging diese Rechnung auf. Die Frauen und die Jugend gehören heute zu den verläßlichsten Stützen des Regimes.

Bis zur Erlangung der Unabhängigkeit, so Sékou Touré vor dem I. Kongreß der P.D.G.-Frauen im Januar 196866, lebte die guineische Frau „dans l'irrésponsabilité, dans la misère" und war Gegenstand einer "disqualification sociale due à une politique d'infériorsation que l'homme d'Afrique lui imposait ....".

Heute dagegen nehmen die Frauen wegen ihrer politischen Bedeutung in der guineischen Gesellschaft einen geachteten und von der Partei beharrlich verteidigten Platz ein. Zwanzig Frauen gehören der Nationalversammlung an (27\% der Sitze). Die Partei zählt 3042 gewählte weibliche Funktionäre.

Mit dem Ruf „Hommes libres de Guinée, allons nous priver nos femmes de la liberté? “67 eröffnete Sékou Touré auf dem V. Parteitag (1959) eine wohlüberlegte Kampagne, deren erste Etappe 1961 mit der Verkündung des sog. „Code des Personnes et des Liberalités" 68 endete. Es setzte unter Hinweis auf den unerträglichen Widerspruch zwischen der staatlichen Einheit des Landes und seiner rechtspolitischen Zersplitterung alle Vorschriften sowohl des zivilen Gewohnheitsrechts als auch des (weitergeltenden) französischen Rechts außer Kraft, soweit sie die in dem neuen Code geregelten Materien betrafen (Personenstandsrecht, Eherecht, Kindschaftsrecht, Erbrecht, Schenkungsrecht).

Insofern wurde erstmals originäres nachkoloniales gemeines Recht geschaffen, womit ein wichtiger erster Schritt zur Vereinheitlichung und Modernisierung des geltenden Rechts getan war. Elemente der Afrikanisierung jedoch enthielt die Neuregelung nicht.

Insbesondere macht der Code, der später um einige Gesetze aus dem Jahre 1962 erweitert wurde, die standesamtliche Eheschließung (vor der religiösen) obligatorisch $^{69}$. Ferner ordnet er an, daß die „dot“, das Brautgeld, künftig nur noch den

65 Moussa Diakité, Bulletin du Ministère de la Justice Nr. 1, Conakry 1965, S. 11 ff.; siehe auch A. Allot, Einführung in das afrikanische Recht, AFRIKA HEUTE v. 1. Juli 1966, S. 191.

66 R. D. A.-Révue Nr. 22, Conakry, März 1968, S. 7 ff.

67 "L'Emancipation de la Femme“, S. Touré, L'Expérience Guinéenne et Unité Africaine, Paris 1962, S. 520 ff.

68 P. D. G., Le Bureau de Presse, Code des Personnes et des Libéralités, Conakry 1967 (hektogr.).

69 Standesbeamter ist seit dem Gesetz Nr. 47/AN/69 nur noch der Commandant d'Arrondissement (bis dahin auch der Gouverneur und der Vorsitzende der örtlichen Parteiorganisation). 
Charakter eines Symbols, nicht mehr den eines Kaufpreises haben dürfe. Die Braut muß mindestens 17, der Bräutigam mindestens 18 Jahre alt sein, und jeder von ihnen die Möglichkeit der freien Entscheidung gehabt haben. Jede Eheschließung, die diesen Vorschriften zuwiderläuft, ist von vornherein nichtig ${ }^{70}$. Zur Scheidung der Ehe bedarf es eines Gerichtsbeschlusses ${ }^{71}$.

Mit Inkrafttreten dieser Vorschriften sollte die Ehe in Guinea aufhören, „ein Geschäft zu sein, durch das die Frau einem beliebigen Mann überlassen wird wie ein simpler Gebrauchsgegenstand, wie ein übertragbarer Eigentumstitel . . "72.

Sékou Touré mußte jedoch erfahren, daß seinem modernen Gesetz, mit dem er die Familie und das Geflecht ihrer Rechtsbeziehungen auf eine zeitgemäße Grundlage stellen wollte, trotz aller oberflächlichen Begeisterung keine Wirksamkeit beschieden war. „Die Erneuerung des sozialen Empfindens und der Mentalität des guineischen Volkes", die der I. Frauenkongreß als Resultat der Reform genannt hat, steht in Wahrheit immer noch aus. Denn sie kollidiert mit den archaischen Produktionsverhältnissen. Diese erwiesen sich als die stärkeren und machen die Befolgung der neuen Vorschriften weitgehend unmöglich. Auch die Vorschriften über das Erb- und Schenkungsrecht sind bislang toter Buchstabe geblieben. Die Volksgerichte wenden in ihrem Schlichtungsverfahren unter stillschweigender Duldung des Regimes nach wie vor örtliches Gewohnheitsrecht an. Dennoch hat das Regime von seinen Reformplänen nicht abgelassen. Erst 1968 wurde in Guinea, einem zu $90 \%$ mohammedanischen Land, die Einehe zum Gesetz erhoben ${ }^{73}$. Das Zustandekommen dieses Gesetzes war ein Musterbeispiel für das Gesetzgebungsverfahren im progressistischen Entwicklungsstaat. Auf „Einladung“ der Partei beschäftigte sich der I. Kongreß der P.D.G.-Frauen im Januar 1968 mit dem Problem der Polygamie und beschloß, wie kaum anders zu erwarten, das Verbot der allgemein üblichen Vielehe als eines Rechtsinstituts, „das eine schwere Bedrohung für die Rechte und die Würde eines Teils der Gesellschaft" darstellt. Diesen Beschluß erhob die Nationalversammlung zum Gesetz. Dem Regime war, wie die Eröffnungsrede Tourés beweist, klar, daß auch dem Verbot der Polygamie ohne tiefgreifende "transformations économiques“, h. h. ohne Änderung der Produktionsverhältnisse, kein Erfolg beschieden sein würde. Es sagte diese daher auch zu. Aber bis heute haben wir nur das Gesetz 4/AN/68 mit seiner unsinnigen Strafandrohung für Zuwiderhandlungen (Gefängnis zwischen 5 und 10 Jahren, Geldstrafe von 5000 bis 500000 F.G.) sowie ein weiteres Gesetz (Nr. 44/AN/69), das auch die Beihilfe zur gesetzwidrigen Eheschließung unter Strafe stellt (1-5 Jahre Gefängnis). Die durch das Verbot der Polygamie ausgelöste soziale Unruhe war beträchtlich. Auf dem Lande verbreitete sich in Windeseile das Gerücht, auch die bestehenden Mehrehen müßten aufgelöst werden; jeder Mann dürfe nur eine Frau behalten; die andere müsse oder könne (!) er zu ihren Verwandten zurückschicken.

Das Gesetz Nr. 4/AN/68 verfügt daher ausdrücklich (Art. 2) den Fortbestand der vor dem 31. Jan. 1968 geschlossenen Mehrehen mit allen ihren Rechtsfolgen nach örtlichem Gewohnheitsrecht. Das Gebot der Einehe ist also im wesentlichen ein Wechsel auf die Zukunft und auf die Jugend, von der es auch bejaht wird. Die Mehrehe ist künftig nur noch in ganz bestimmten, medizinisch gerechtfertigten Fällen zulässig, etwa bei Unfruchtbarkeit, Art. 3.

70 Gesetz Nr. 54/AN/62 (s. auch Art. 132 ff. Code des Personnes et des Libéralités).

71 Gesetz Nr. 57/AN/62.

72 "L'Emancipation de la Femme“ a. a. O. 
Um jeder mißbräuchlichen Auslegung des Gebots der Einehe, insbesondere einer "Scheidungswelle", vorzubeugen, erschwert das Gesetz Nr. 4/AN/68 die Ehescheidung außerordentlich, welche bis dahin, aufgrund des Gesetzes Nr. 57/AN/62, relativ leicht zu erreichen war. Es gab die Scheidung im gegenseitigen Einvernehmen der Ehegatten sowie die Scheidung aufgrund Antrags eines der beiden Ehegatten. Die Scheidungsgründe waren, anders als im ursprünglichen "Code des Personnes et des Libéralités“, nicht enumerativ. Im Grunde war es noch wie ehedem: „Ein Nichts konnte die Scheidung provozieren, und selbst wenn die Frau ihrem Mann 1001 Freuden bereitet und ihm 20, 30 Jahre lang getreulich moralischen und materiellen Beistand geleistet hatte, konnte sie sich plötzlich auf der Straße wiederfinden, ohne ein Obdach, ihrer Kinder beraubt und gezwungen, die ,dot' zurückzuzahlen sowie den Wert der Schmuckgegenstände, Kleider und sonstigen Hochzeitsgeschenke zu erstatten ...“(A. S. Touré, Bd. VI, S. 347 ff.). Nach der nunmehr gültigen Neuregelung darf die Ehe nur noch geschieden werden, wenn Gründe vorliegen, „die die Aufrechterhaltung des ehelichen Bandes menschlich unzumutbar machen, sei es das totale Fehlen gegenseitigen Vertrauens, sei es eine für den anderen entwürdigende Nichtachtung der ehelichen Rechte und Pflichten", Art. 4.

So revolutionär das Gebot der Zivilehe, die Festsetzung des Heiratsalters für Mädchen auf 17 Jahre, das Gebot der freien Gattenwahl, das Verbot des Frauenkaufs, die Einführung eines gewissen Schutzes für die Frau im Scheidungsrecht und schließlich das Gebot der Einehe in einer noch weithin archaischen Gesellschaft auch sind, es wird langer Jahre "kultureller Revolution“ bedürfen, bis diese Reformen sich durchgesetzt haben. Denn es ist dies ein Bereich menschlichen Lebens, in dem wie überall in der Welt - Verwaltungszwang nur sehr bedingt ausgeübt werden kann.

An seine Stelle versucht die Partei über ihre Jugendorganisation J.-R.D.A. eine Art Gewissenszwang zu setzen. So beschloß der letzte J.-R.D.A.-Kongreß (März 1968), daß in Zukunft jede religiöse Eheschließung ohne vorausgegangene standesamtliche Trauung als Konkubinat, als getarnte Form der Polygamie, zu gelten habe. Er beschloß ferner das Verbot der "malle d'habit", der wohlgefüllten Aussteuerkiste, die der Bräutigam der Braut bisher zum Geschenk machen mußte, sowie aller Geldforderungen der Brauteltern an den Bräutigam. Schließlich forderte der Kongreß alle Jugend- und Militärfunktionäre auf, über die Einhaltung dieser Vorschriften zu wachen.

\section{c) Das Bodenrecht}

Als Gegenstück zur Reform der sozialen Beziehungen durch Neuordnung des Eherechts ist die Vergesellschaftung von Grund und Boden als Voraussetzung für die noch ausstehende Änderung der Produktionsverhältnisse zu werten. Diese Vergesellschaftung wird - um sie plausibler erscheinen zu lassen - als eine Rückkehr zur vorkolonialen, also „afrikanischen“ Ordnung interpretiert, welche nur kollektives Grundeigentum auf Dorfebene gekannt habe.

Zumindest in Fouta Djallon aber, wo sich feudalistische Herrschaftssysteme mohammedanischer Eindringlinge entwickelt hatten, gab es auch - durch Land- 
nahme - privates Grundeigentum, das sich in der Familie des Eroberers weitervererbte und dem ursprünglichen Eigentümerkollektiv gegen eine Grundrente zur Nutzung überlassen worden war ${ }^{74}$.

Außerdem kannte man hier und da im vorkolonialen Guinea das allen anderen Rechtstiteln überlegene „droit du premier occupant" und seiner Nachkommen.

Die Kolonialmacht unterschied drei Formen von Grundstücksrechten:

a) das sogenannte livret foncier, durch das die Administration indigenes Gewohnheitsrecht an Grund und Boden nachträglich verbriefte und sich jedes eigenen Anspruchs darauf begab;

b) den sogenannten permis d'habiter, durch den die Administration (in den Städten) widerrufliche Wohnrechte auf bebauten und auf ihren Namen in den Kataster eingetragenen Grundstücken gewährte, die allerdings zu vollem Eigentum erstarken konnten;

c) den sogenannten titre foncier, dessen Inhaber von vornherein ausschließliches Eigentum an dem fraglichen Grundstück genoß.

Unvergessen ist die französische Politik hinsichtlich der „terres vacantes et sans maître", die in den Auseinandersetzungen mit der Kolonialmacht vor Erlangung der Unabhängigkeit eine beträchtliche Rolle spielte. Trotz entgegenstehender Vorschriften (Senatus-Consultus v. 1852 und Dekret v. 1906) hatte die Kolonialverwaltung nämlich Grundstücksrechte von Afrikanern stets als prekär betrachtet „à la merci d'un déguerpissement au gré de l'Administration pour le profit d'un Commerçant ou d'un industriel quelquonque"75. Im Jahre 1955 hatte daher die guineische Presse an die Metropole appelliert, alle zwischen 1911 und 1953 vorgenommenen Überführungen von Grundstücken in das Eigentum des französischen Staates zu überprüfen „afin de réparer une spoliation que déshonore la République et l'Union Française" (ebenda).

Wie manche andere, so erledigte sich auch diese Forderung durch die überraschende Erlangung der Unabhängigkeit. Für die Regierung Sékou Touré war die Verstaatlichung bzw. die Vergesellschaftung der „secteurs clefs“ der nationalen Wirtschaft von vornherein beschlossene Sache. Außer der Energieerzeugung, den Verkehrsmitteln, dem Außenhandel, den Banken und Versicherungen sowie den Bodenschätzen gehörte dazu auch das Eigentum an Grund und Boden.

Doch das Regime ging mit Rücksicht auf die Empfindlichkeiten der ländlichen Massen und der Lokalmatadore behutsam, in drei Etappen, zu Werke:

1. Etappe. Das Dekret Nr. 242 PRG vom 20. Oktober 1959 ändert zwar noch nichts an den bestehenden Eigentumsverhältnissen, unterwirft aber alle Verkäufe, Belastungen und Abtretungen von Grundstücksrechten der vorherigen Genehmigung durch den Minister für Öffentliche Arbeiten. Vorerst also wird nur das Verfügungsrecht eingeschränkt, hierdurch jedoch bereits ein erster Schlag gegen den geltenden Eigentumsbegriff geführt.

\footnotetext{
74 A. Amin, Trois Expériences Africaines du Développement: Le Mali, La Guinée et la Ghana, Paris 1965, S. $10 \mathrm{tt}$.

75 „La Propriété Foncière et les Guinéens in „La Liberté“ vom 8. März 1955.
} 
2. Etappe. Das Dekret Nr. 027 PRG vom 20. Februar 1961 ist der nächste Schritt. Jeder Inhaber eines „titre foncier“ an einem unbebauten Grundstück muß dieses binnen einer Halbjahresfrist bestellen oder bebauen, anderenfalls es entschädigungslos dem Staat verfällt. In der Praxis bedeutet das: aller unbebauter Grund und Boden ist Staatsbesitz. Private können mit unbebauten Grundstücken keine Rechtsgeschäfte mehr tätigen.

Ein halbes Jahr später stellt der Minister für Öffentliche Arbeiten in einem Rundschreiben (Nr. 151 NTP vom 2. November 1961) befriedigt fest, daß dem Staat infolge des o. a. Dekrets eine große Menge von Grundstücken zugefallen sei. Das Rundschreiben schließt mit der Mitteilung an die Öffentlichkeit „que tous le terrains nus, récuperés par l'Etat guinéen sont exclusivement réservés à ses propres besoins ....".

3. Etappe. Das Dekret Nr. 025 PRG vom 10. Januar 1962 bestimmt, daß hinfort Gegenstand eines Immobiliengeschäfts nur noch ein Gebäude, nicht mehr das dazugehörige Grundstück sein kann: „le terrain nu faisant obligatoirement retour au domaine de l'Etat guinéen, propriétaire de droit".

Der Privatmann kann künftig also nur noch einen mit einer Art Pachtzins verbundenen "permis d'occuper" erwerben, der nur mit behördlicher Genehmigung veräußert werden darf.

Damit war der Prozeß der Vergesellschaftung des Produktionsmittels Boden auf bemerkenswert kaltem Wege abgeschlossen. Doch blieb er für die Produktionsverhältnisse bislang ohne Bedeutung, denn die Besitzverhältnisse änderten sich nicht. Der Genossenschaftsgedanke vermochte nicht Fuß zu fassen. Die Pläne der Regierung, die gesamte Kaffee-, Palmöl-, Tabak- und Reiserzeugung zu verstaatlichen ${ }^{76}$, scheiterten im Vorfeld.

Die alten Eigentümer oder Eigentümerkollektive verfügen daher faktisch weiter über Grund und Boden, sofern dieser bebaut oder landwirtschaftlich genutzt ist (Dekret Nr. 170 PRG vom 5. Mai 1962), dies um so mehr, als bisher versäumt worden ist, die o. a. Rechtstitel der Vergangenheit samt und sonders in den seit 1962 allein erhältlichen „permis d'occuper“ umzuwandeln. Man vertraut offenbar darauf, daß die alten Rechte mit ihren Inhabern aussterben werden.

Zwei unmittelbare Wirkungen hat die Vergesellschaftung von Grund und Boden jedoch gehabt, eine erwünschte, indem sie die Spekulation unterband ${ }^{77}$, und eine unerwünschte, indem sie es dem privaten Bauherrn nahezu unmöglich macht, sich Baugeld durch Aufnahme einer Hypothek zu beschaffen.

Alles in allem wird die Vergesellschaftung von Grund und Boden für einen sich als sozialistisch verstehenden Staat wie Guinea, der öffentliches und Privatinteresse prinzipiell nicht als Gegensatz begreift, als "la seule doctrine viable“ angesehen. Grund und Boden sind öffentliches Eigentum, dessen Verwaltung im Interesse der Gemeinschaft zu erfolgen hat ${ }^{73}$. Daß diese Formel in hohem Grade unpopulär ist, hat das Regime sich selbst zuzuschreiben, d. h. seiner Unfähigkeit zu konstruktiver Agrar- und Kommunalpolitik.

\footnotetext{
76 Direction de la Statistique et de la Mécanographie, Essai sur l'orientation économique de la Guinée Nouvelle, Conakry, März 1959

77 Allerdings ist mittlerweile doch eine beträchtliche illegale Spekulationstätigkeit zu beobachten, deren der Staat nicht Herr zu werden vermag.
} 


\section{d) Das Arbeits- und Sozialrecht}

Der Verfassungsartikel 44 garantiert allen Bürgern der Republik ein gleiches Recht auf Arbeit, Erholung, soziale Leistungen und Bildung. Er garantiert ferner das Streikrecht und das Recht auf gewerkschaftlichen Zusammenschluß.

Zur Verwirklichung des damit umrissenen Programms ergingen 1960 zwei Gesetze, der Code du Travail und der Code de la Sécurité Sociale. Ein Gemeinschaftswerk des Gewerkschaftsbundes C. N. T. G., der Nationalversammlung sowie des Arbeitsund Sozialministeriums, fanden sie „sowohl wegen ihrer Einfachheit und Klarheit als auch wegen ihres demokratischen und progressistischen Inhalts" ein günstiges Echo in der guineischen Öffentlichkeit ${ }^{79}$.

Zwar brachten sie nicht gleich, wie die offizielle Apologetik behauptet, dem gesamten guineischen Volk eine Verbesserung seiner Arbeits- und Lebensbedingungen, sondern nur den Lohn- und Gehaltsempfängern, aber auch dies war schon ein beträchtlicher Schritt vorwärts, zumal damit gerechnet werden konnte, daß sich der begünstigte Personenkreis von Jahr zu Jahr erweitern würde.

Der Code du Travail (Gesetz Nr. 1/AN/60, verkündet durch Dekret Nr. 197 PRG vom 21. Juli 1960), der die Arbeitsverhältnisse außerhalb des öffentlichen Dienstes regelt (Art. 2), unterscheidet sich auf den ersten Blick nur wenig von dem bis dahin geltenden Arbeitsgesetzbuch der Kolonialmacht, dem sog. Code du Travail des Territoires d'Outre-Mer (französisches Gesetz Nr. 52-1322 vom 15. Dezember 1952). Seine „solide Armatur“ wurde übernommen. Ansonsten aber war der guineische Gesetzgeber bemüht, ihn zu „dekolonialisieren “80.

Zweck dieser Dekolonialisierung des Arbeitsrechts war die Ausmerzung aller Vorschriften, die allein den Interessen der Kolonialmacht gedient hatten oder gar den Stempel des Paternalismus trugen.

Der Arbeitsvertrag, bisher „passé librement“, ist nunmehr den Regeln des Gemeinen Rechts unterworfen und dadurch, wie man glaubt, der Gefahr der willkürlichen Formulierung bzw. Auslegung entzogen (Art. 30). Das sog. tâcheronnat, d. h. die Vermietung von Arbeitskräften durch Zwischenunternehmer für bestimmte Arbeiten oder Dienstleistungen gegen Honorar, vom kolonialen Arbeitsrecht zugelassen, ist, weil als Form der Ausbeutung gewertet, streng untersagt (Art. 98). Für den Arbeitsvertrag, gleich welcher Dauer, ist nunmehr Schriftform vorgeschrieben. Nach kolonialem Arbeitsrecht war die Schriftform nur bei längerfristigen Arbeitsverträgen obligatorisch. Die Probezeit, unter dem alten Regime 6 Monate für Afrikaner, 12 Monate für Europäer, wurde auf 3 bzw. 6 Monate herabgesetzt (Art. 34). An die Stelle des "Office de la Main-d'oeuvre“ des alten Art. 174, das nur für die Vermittlung exterritorialer Arbeitskräfte nach Guinea („diriger les travailleurs d'une métropole vers un territoire assujetti“) zuständig war, trat das sog. "Office National de la Main-d'oeuvre“ (Art. 221 ff.). Seine Aufgabe besteht in der Befriedigung des Arbeitskräftebedarfs der Entwicklungswirtschaft und in der Herbeiführung des allerdings noch weit entfernten Zustandes der „Vollbeschäftigung" 81 .

\footnotetext{
78 De la Réglémentation Domaniale depuis 1958 et des Conséquences du Nouveau Régime, Révue du Développement Economique, Nr. 3, Conakry, November 1964.

79 Code du Travail - Sécurité Sociale - Retraite, R. D. A.-Révue Nr. 20, Conakry, Dezember 1967, S. 33 ff.

80 Cisse Fodé, damals Arbeitsminister, in einer Rundfunkerklärung vom 7. Januar 1961.

$81 \mathrm{Mme}$. Fofana Fodé, La nouvelle Législation Sociale de la République de Guinée, le Code du Travail, Recherches Africaines Nr. 3, Conakry, Juli/September 1961, S. $38 \mathrm{ff}$.
} 
Die Konventionalstrafen für Verstöße des (privaten) Arbeitgebers gegen die arbeitsrechtlichen Vorschriften, unter dem alten Regime (Art. $221 \mathrm{ff}$.) eher symbolischen Charakters, wurden drastisch verschärft (Art. 284 ff.). Zahlreiche Bestimmungen, die unter dem alten Regime fakultativ gehandhabt werden konnten, wurden jetzt obligatorisch, so die Führung von Lohn- und GehaltsTisten in allen Betrieben (Art. 218) und das Paßbild auf der Arbeitskarte (Art. 220). Vor allem aber müssen jetzt alle Kollektivverträge genaue Regelungen für Versetzung und Entlassung, für Frauen- und Kinderarbeit sowie für Zuschläge bei schwieriger, gefährlicher oder schmutziger Arbeit enthalten (Art. 106).

Schließlich enthält das neue guineische Arbeitsgesetzbuch eine an sich vorbildliche, den tatsächlichen Möglichkeiten der Lehrlingsausbildung jedoch weit vorauseilende Regelung des Lehrlingsrechts (Art. 82 ff.).

Andere Vorschriften wie die Gewährung des Streikrechts (Art. 257 ff.) und die Freiheit des gewerkschaftlichen Zusammenschlusses (Art. 4 ff.) sind inzwischen fragwürdig geworden 82 . Wiederum andere, wie der Grundsatz "gleicher Lohn für gleiche Arbeit" (Art. 123), wie der in Schwarz-Afrika beispielhafte Mutterschutz (freie Entbindung, 14 Wochen voll bezahlter Schwangerschaftsurlaub usw., siehe Art. 147 ff.), und die freie betriebliche Heilfürsorge für alle Belegschaftsmitglieder nebst ihren Angehörigen (Art. 186 ff.) spielen eine immer größere Rolle und werden erstaunlich gewissenhaft befolgt.

Auch der Rechtsschutz des Arbeitnehmers in arbeitsrechtlichen Streitigkeiten mit dem (privaten) Arbeitgeber (Art. $226 \mathrm{ff}$.) wurde wesentlich verbessert und die Stellung des sogenannten „Inspecteur du Travail“ (Art. 193 ff.) sowie des Betriebsrats (Art. $211 \mathrm{ff}$.) gestärkt. Schon vorher, durch Dekret Nr. 127 MT-CAB, war ausländischen Arbeitnehmern das Recht aberkannt worden, als Arbeitsrichter (Laienrichter) tätig zu sein. Berufsgruppen wie die Journalisten und Handelsvertreter, deren Arbeitsverhältnisse in Frankreich besonderen Gesetzen unterliegen, bezog das guineische Arbeitsgesetzbuch in seinen Geltungskreis mit ein (Art. $41 \mathrm{ff}$.). Hier aber wird schon die Grenze sichtbar, die der Geltung eines ausdrücklich nur für Arbeitsverhältnisse außerhalb des öffentlichen Dienstes geschaffenen Arbeitsrechts im progressistischen Staat gezogen ist: Die Zeitungen und die wichtigsten Industriebetriebe des Landes sind staatlich; es dürfte in Guinea zur Zeit weder einen Journalisten $^{83}$ noch einen Handelsvertreter geben, auf den die einschlägigen Vorschriften des Code du Travail Anwendung finden. Außerdem wurde jede freiberufliche Tätigkeit durch Dekret Nr. 253 PRG vom 23. Juni 1964 untersagt. Im übrigen mißt der progressistische Entwicklungsstaat mit zweierlei Maß, je nachdem, ob der Arbeitgeber ein Privatmann oder die öffentliche Hand ist: den ersteren, ohnehin eingeschüchtert durch die sozialistische Attitude des Staates, trifft die ganze Härte des Gesetzes; auch der geringsten Verpflichtung, die ihm der Code du Travail auferlegt, kann er sich nicht entziehen. Für ihn bedeutet ein Konflikt mit seiner Belegschaft sofort den Konflikt mit der Staatsgewalt.

Die öffentliche Hand dagegen kann es sich erlauben (und tut es auch), sehr viel weniger skrupelös zu sein. So kommt es dahin, daß in großen Privatunternehmen (Fria) ein besseres Arbeitsklima herrscht als in vergleichbaren Staatsbetrieben.

82 Zur Rolle der Gewerkschaftsbewegung im progressistischen Entwicklungsstaat siehe: A. S. Touré, Vingtième Anniversaire et Huitième Congrès du P. D. G., Bd.XVI, Conakry 1967, S. $118 \mathrm{ff}$., Le Travailleur (Waliké), Zentralorgan der C. N. T. G., Nr. 1-9, Conakry, März-Oktober 1968; HOROYA-Hebdo Nr. 1665-19 u. 1666-20, Conakry, Mai 1969 (Berichterstattung über den V. C. N. T. G.-Kongreß).

83 Außer vielleicht dem Redakteur des hektographiert erscheinenden Bistumsblattes "Alléluja“. 
Auch der Code de la Sécurité Sociale (Gesetz Nr. 21/AN/60, verkündet durch Dekret Nr. 103 PRG vom 31. März 1961), kommt nur den Lohn- und Gehaltsempfängern im privatrechtlichen Beschäftigungsverhältnis zugute.

Dieses Gesetz regelt insoweit die Kranken-, Invaliden- und Hinterbliebenenversorgung, die Familienbeihilfe (Kindergeld, Wochengeld usw.) sowie die sozialen Leistungen nach Arbeitsunfällen.

Die Kosten dieses Sozialwerks tragen ausschließlich der Staat und die Arbeitgeber (Art. 16 ff.). Vom Arbeitnehmer werden keinerlei Beiträge zur Kranken-, Unfall-, Invaliden- und Rentenversicherung erhoben.

Während die Verwaltung dieser Risiken einer sogenannten Caisse National de Sécurité Sociale (ordonnance Nr. 008 MT/CNSS vom 10. Februar 1960) obliegt, der alle Arbeitnehmer meldepflichtig sind, werden die Pensionen der Staatsfunktionäre und Soldaten sowie ihrer Hinterbliebenen aus dem Fonds der Caisse Nationale de Retraites gezahlt. Auch sie brauchen, anders als in der Kolonialzeit, keinerlei Beiträge $\mathrm{zu}$ ihrer Pensionskasse $\mathrm{zu}$ leisten ${ }^{84}$. Renten und Pensionen wurden von 1959 bis 1967 um bis zu $65 \%$ erhöht, was allerdings durch den in dieser Zeitspanne eingetretenen Kaufkraftschwund mehr als wieder ausgeglichen wurde. Auch zwischen den sozialpolitischen Intentionen und Möglichkeiten des progressistischen Entwicklungsstaates besteht also eine große Diskrepanz. Am deutlichsten läßt sich dieses Phänomen am Beispiel des Dekrets Nr. 82 PG vom 11. März 1959 demonstrieren, das "allen Bürgerinnen“ ohne Unterschied das Recht auf freie Krankenhausentbindung einräumt. Mangels Krankenhäusern und Ärzten ${ }^{85}$ konnte dieses Gesetz auch 1970 nur von einem geringen Bruchteil der werdenden Mütter in Anspruch genommen werden.

\section{e) Das Strafrecht}

Beispielhaft für die Funktionalisierung des Rechts im progressistischen Entwicklungsstaat ist der Geist - nicht so sehr der Buchstabe - , der das neue guineische Strafgesetzbuch von 1965, den Code Pénal, beherrscht ${ }^{86}$. Die materiellen Änderungen gegenüber dem bis dahin noch in Geltung gewesenen französischen Strafrecht sind rasch aufgezählt; auch hier wurde die „solide Armatur" übernommen. Gleichwohl manifestieren sie, nach den Worten des guineischen Generalstaatsanwalts, den späten ${ }^{87}$, dafür aber gründlich vorbereiteten Bruch „avec une éthique qui n'est pas la notre". Ein Strafgesetzbuch ist nach guineischer Auffassung nichts anderes als ein System von "règles de conduite qu'un peuple librement et démocratiquement a décidé de s'imposer pour assurer... l'ordre, l'harmonie et la paix dans la cité"

Folgerichtig wurde die guineische Strafrechtsreform weder einem Ausschuß der Nationalversammlung noch einer Sachverständigengruppe im Justizministerium überlassen. Vielmehr wurde sie zur Sache des ganzen Volkes gemacht. Dieses

84 R. D. A.-Révue Nr. 20, Conakry, Dezember 1967, S. 33 ff. Diese Kasse zahlt auch die Militärpensionen aus der Kolonialzeit, deren Zahlung Frankreich 1965 eingestellt hat, Guinea leitet daraus eine Forderung an Frankreich von bereits über $7 \mathrm{Mrd}$. FF ab.

85 Nach der Statistik der Fonction Publique standen Ende 1967 für rd. 4 Mio. Einwohner 97 Arzte zur Verfügung, davon 58 Ausländer.

86 Gesetz Nr. 43/AN/65 vom 21. September 1965, verkündet durch Dekret Nr. 313 PRG vom 30 . Oktober 1965, J. O. R. G. Jahrgang 1965, Nr. 22, S. 308.

87 Die Republik Mali z. B. gab sich bereits 1961 ein eigenes Strafgesetzbuch (Gesetz Nr. 99 v. 3. August 1961).

88 Keita Fadiala, Le Code Pénal Guinéen et les Principes directeurs de la Législation Guinéenne, R. D. A.Révue Nr. 15, Conakry, März 1967, S. $89 \mathrm{ff}$. 
erhielt Gelegenheit, in den Parteiorganisationen, von der Basis bis zur Spitze, über den Entwurf zu beraten und Änderungsanträge zu stellen. Mehr als die Hälfte der Artikel soll „à la suite de débats passionnés et passionnants“ erhebliche Anderungen erfahren haben, bevor der Nationale Revolutionsrat den Entwurf in seiner Gesamtheit billigte und ihn der Nationalversammlung zur abschließenden Behandlung überwies.

Die vorgenommenen Änderungen und Ergänzungen gegenüber dem französischen Code Pénal bringen das geltende Strafrecht in Einklang mit den veränderten politischen, sozialen und wirtschaftlichen Gegebenheiten des unabhängigen Staates. Insbesondere stellt das neue Strafgesetzbuch (34 ff.) die säumigen Schuldner des Staates und der Staatsbetriebe unter Strafe. Die Tatsache, daß der französische Code hierzu keine Handhabe bot, hatten sich zahlreiche Händler zunutze gemacht „pour emprunter à nos banques et à nos comptoirs des sommes importantes avec l'intention de ne jamais rembourser".

Erfolgte diese Änderung zum Schutze der staatlichen Wirtschaft, so wurden andere Straftatbestände wie die des Rassismus und des Regionalismus (Art. 109 ff.) zum Schutz der nationalen und territorialen Einheit neu geschaffen.

Mit den Artikeln 223 ff. („vagabondage“) schuf sich das Regime die Möglichkeit, der Landflucht strafrechtlich $z u$ begegnen. Einem anderen, weit verbreiteten sozialen Mißstand, nämlich dem der böswilligen Verlassung und Versäumung der Unterhaltspflicht gegenüber der meist zahlreichen Familie sucht das Gesetz in Artikel 311 zu steuern, indem es die Strafandrohung des französischen Code Pénal, die nur für Frauen galt, auf die Männer ausdehnt. Es wird darin ein wichtiger Schritt zur Verwirklichung des Gleichheitsgrundsatzes gesehen.

Angesichts der hohen Amtskriminalität von grundsätzlicher Bedeutung ist schließlich die dem Täter von Eigentumsdelikten an öffentlichen Sachen oder Mitteln eingeräumte Möglichkeit, sich durch materielle Wiedergutmachung des angerichteten Schadens eine beträchtliche Strafmilderung zu erkaufen, d. h. „durch einen Akt der Reue Mitleid und neues Vertrauen der Gesellschaft zu erwerben "89.

Aber der progressistische Entwicklungsstaat vermag seinem neuen Strafgesetzbuch - wie anderen von ihm gesetzten Normen auch - erst allmählich Geltung zu verschaffen. Noch 1968 hatte das Staatssekretariat der Justiz Anlaß, die guineischen Richter für die häufige Anwendung von durch das neue Strafgesetzbuch aufgehobenen Vorschriften zu rügen ${ }^{90}$.

Es sei dies, so heißt es a. a. O., eine Anomalie „qui ne saurait se prolonger... sans porter un grave préjudice à notre . . . volonté de rompre . . . avec le passé colonial“. Im übrigen hält es das Staatssekretariat der Justiz für angezeigt, den guineischen Gerichten einige einfache, aber offenbar auch im progressistischen Entwicklungsstaat unerläßliche Prinzipien ins Gedächtnis zurückzurufen. Es sind dies das Verbot der Analogie im Strafrecht, der Grundsatz „nullum crimen sine lege" und das nicht minder wichtige Gebot "poenalia sunt restringenda" (a. a. O. beide lat. zitiert), letzteres als Beweis für den „respect que notre droit pénal, inspiré de notre principe révolutionnaire . . . conserve pour les libertés que notre Parti garantit à chaque citoyen“.

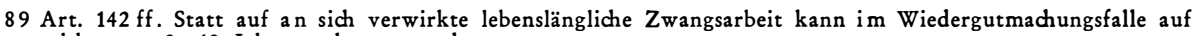
solche von 2-10 Jahren erkannt werden.

90 Présidence de la République, Secrétariat d'Etat chargé de la Justice: Extrait des Conférences tenues par le Président de la Cour d Appel dans les Juridictions de la Guinée Forestière, Conakry 1968 (hektogr.). 
Wegen Verletzung dieser elementaren Grundsätze ist beim Cour d'Appel in Conakry eine Fülle von Verfahren anhängig. Das am wenigsten befolgte Verbot scheint aber das der Rückwirkung von Strafgesetzen zu sein, zumal es verfassungsrechtlich nicht abgesichert ist. Das Staatssekretariat der Justiz bezeichnet die Mißachtung dieses Verbots als „impardonnable“, läßt aber die Frage offen, ob es auch in politischen Strafsachen Geltung haben soll. Dennoch muß die Redlichkeit erstaunen, mit der hier der Versuch unternommen wird, eine Rechtsethik zur Geltung zu bringen, ein Stück Rechtsstaat zu verwirklichen.

Als wäre Guinea kein revolutionärer Staat, der seine Interessen in Wahrheit höher stellt als das Gebot der Rechtssicherheit, heißt es in dem Dokument, im Interesse eben dieser Rechtssicherheit müsse vor späterer strafrechtlicher Verfolgung sicher sein, wer die zur Tatzeit geltenden Gesetze befolgt hat. Niemand sei ein strafrechtlich relevanter Vorwurf zu machen, der ein Gesetz verletzt habe, das es zur Tatzeit noch gar nicht gab.

Dieses für guineische Verhältnisse überraschende Bekenntnis zu Grundelementen rechtsstaatlicher Praxis zeigt aber nur um so deutlicher die Kehrseite der Medaille, die unsichere Wirklichkeit, die sich leider nicht am unwandelbaren Gesetz, sondern an der Partei orientiert, welche das Gesetz beugt oder ignoriert, wann immer sie das für nötig hält.

Rechtsunsicherheit, vor allem hinsichtlich der Rückwirkung von Strafgesetzen, hatte auch schon vor Inkrafttreten des Code Pénal bestanden. Zwischen 1958 und 1965 wurden nämlich in Konkurrenz zum noch geltenden französischen Strafrecht drakonische ad-hoc-Gesetze ${ }^{91}$ erlassen, die samt und sonders auch dann rückwirkend angewandt worden sind, wenn sie härter als die entsprechenden älteren Vorschriften waren. Das gilt vor allem für die Ordonnance Nr. 14 MJ-PG vom 14. Februar 1959 zur Bekämpfung der damals überhandnehmenden Diebstahls- und Verkehrskriminalität (Todesstrafe für qualifizierten Diebstahl und für fahrlässige Tötung bei Verkehrsdelikten), später abgelöst durch das etwas mildere Gesetz Nr. 63/AN/62 vom 31. August 1962.

Weiter ist in diesem Zusammenhang das Gesetz Nr. 75/AN/62 zu nennen, das für Eigentumsdelikte an öffentlichen Mitteln und Sachen sowie für Währungsund Zollvergehen außer den ordentlichen Strafen die Vermögensbeschlagnahme androht. Diese Vorschrift ist später, durch das Gesetz Nr. 11 AN/CP/64, auch auf das in Afrika so häufige Delikt des Viehdiebstahls ausgedehnt worden.

Schließlich gehören hierher auch die zahlreichen Vorschriften zur Bekämpfung der Wirtschaftskriminalität, die das Regime nach dem Vorbild der sozialistischen Länder seit 1958 erlassen hat, und nicht zuletzt die 24 Punkte des sog. Loi-Cadre vom 8. November 1964/68, mit denen typisches Ausnahmerecht außerhalb des Code Pénal, außerhalb der ordentlichen Gerichtsbarkeit geschaffen worden ist, was die Rechtssicherheit nicht eben vergrößert. Aber man muß das nüchtern betrachten. Im progressistischen Staat, wenigstens auf der ersten Stufe seiner Entwicklung scheint Rechtssicherheit allenfalls unter Ausklammerung des politischen Strafrechts realisierbar zu sein: Staatssicherheit geht vor Rechtssicherheit.

Mit den Verbrechen und Vergehen gegen die äußere und innere Sicherheit des Staates, gegen die Verfassung sowie gegen die öffentliche Ordnung beschäftigt sich der Code Pénal in seinem III. Buch. Die Strafdrohungen sind, dem Charakter

91 Diese Vorschriften wurden zum Teil in den neuen Code Pénal einbezogen. 
des Regimes entsprechend, drakonisch. Das Urteil des Revolutionsgerichts gegen die Teilnehmer des Komplotts vom Frühjahr $1969^{92}$ ließ - anders als die Urteile vom Januar 1971 - ein vordergründiges Bestreben erkennen, auch bei der Ahndung politischer Straftaten die Form des regulären Strafprozesses wenigstens in etwa zu wahren. Die Strafzumessungen wurden, wenn auch nicht einzeln, so doch kumulativ begründet. Das Komplott im ganzen erfüllte danach die Tatbestände der Artikel 68, 72, 75, 80, 81, 251, 255, 323 und 325 des Code Pénal. Für die in contumaciam gefällten Todesurteile gegen die beiden Hauptangeklagten wurde auf die entsprechenden Artikel 244/245/246 der neuen Strafprozeßordnung (Code de Procédure Pénale) ${ }^{93}$ Bezug genommen. Damit aber hörte die Wahrung des schönen Scheins schon auf. Denn daß der Nationale Revolutionsrat, wie geschehen, durch Gesetz der Nationalversammlung zum Revolutionstribunal erhoben werden kann und dann als solches für die Ausübung der politischen Strafjustiz zuständig ist, sieht die Strafprozeßordnung von 1966 nicht vor, obgleich zu dieser Zeit das "Tribunal Revolutionnaire" bereits ein Begriff war. Der Strafprozeßordnung zufolge gehören nach wie vor alle Verbrechen und Vergehen gegen die Staatssicherheit in die "seule compétence ratione materiae d'une juridiction d'exception appelée Haute-Cour de Justice" (Art. 335).

Dieser Gerichtshof wäre also der gesetzliche Richter gewesen, nicht der Nationale Revolutionsrat als Tribunal Revolutionnaire oder - wie im Januar 1971 - gar die Nationalversammlung. Streng genommen werden politische Angeklagte also ihrem gesetzlichen Richter stets entzogen. Leider ist die Frage, wie die politische Rechtsprechung im progressistischen Entwicklungsstaat gewertet werden muß, wenn sie durch ein Gericht erfolgt, das nach der Prozeßordnung nicht nur nicht zuständig, sondern nicht einmal existent ist, sehr akademisch. Allenfalls läßt sie sich aus dem besonderen Begriff der Volkssouveränität beantworten, als deren Trägerin sich die Partei des progressistischen Entwicklungsstaates versteht.

Schon anläßlich des I. Komplotts (Frühjahr 1960) hatte Sékou Touré erklärt, das Politbüro lehne es angesichts der Tragweite der Ereignisse ab, die Untersuchung der Verschwörung „à un quelquonque organisme d'Etat“, d. h. einem Gericht, $\mathrm{zu}$ übertragen: „Seule la vigilance du peuple tout entier pouvait sauver le pays..." ${ }^{\text {94. }}$

\section{Das Notstandsrecht des Loi-Cadre}

Nirgends offenbart das Recht der „permanenten Revolution“, d. h. des permanenten Notstands, seinen Charakter als politische Waffe unbarmherziger als in den Vorschriften des aus der Konfrontation mit dem seiner Natur nach konterrevolutionären Kleinbürgertum hervorgegangenen Loi-Cadre. Im Herbst 1964 erstmals aufs höchste alarmiert, sah die Einheitspartei Sékou Tourés die Errungenschaften der Revolution akut gefährdet, durch eine "catégorie de profiteurs malhônnêtes de la révolution“. Die Bevölkerung nahm mehr und mehr eine abwartende Haltung ein. Der Staatsapparat begann, deutliche Spuren von Desorganisation zu zeigen. "La marche normale de l'Histoire de notre Peuple vers ses

92 HOROYA-HEBDO Nr. 1664-18 vom 17. bis 23. Mai 1969, S. $16 \mathrm{ff}$.

93 Gesetz Nr. 64/AN/66 vom 21. September 1966, verkündet durch Dekret Nr. 363 PRG v. 22. Oktober 1966.

94 De l'action subversive au complot armé, A. S. T. Touré, La Révolution Guinéenne et le Progrès social, Bd. VI, Conakry 1962, S. $21 \mathrm{ff}$. 
nobles objectifs d'émancipation totale "95 drohte, so Sékou Touré a. a. O., eine falsche Richtung einzuschlagen. Die Wirtschaftslage Guineas schien vollends ruiniert. Am 8. November 1964 - der November als erster Monat nach der langen Regenzeit ist immer ereignisträchtig in Guinea - zog das Regime die Konsequenzen. Auf einer eilig einberufenen Massenversammlung im Stadion von Conakry führte Sékou Touré den zwar erwarteten, in seiner Härte aber überraschenden „coup d'arrêt" gegen die faktische Allianz des Kleinbürgertums mit - wie es hieß - Imperialismus, Kolonialismus und Neokolonialismus. Unter leidenschaftlichen Ausfällen gegen die „étrangleurs de notre liberté" verkündete er die 12 „Punkte“ des „Loi-Cadre de l'action militante du Parti Démocratique de Guinée" 96 . Zehn Tage später verabschiedeten Nationalversammlung und Nationaler Revolutionsrat in gemeinsamer Sitzung die Ausführungsvorschriften ${ }^{97}$. In einer glänzenden, an Danton oder Robesspierre erinnernden Rede stellte Sékou Touré die Beamten und Parteikader mit den Händlern auf eine Stufe. Die Totengräber der guineischen Wirtschaft, die Liquidatoren des Staates, die Demoralisatoren der öffentlichen Meinung, so rief er aus, „se recrutaient parmi les commerçants et les responsables politiques et administratifs du pays".

Das Regime glaubte dann lange Zeit, sich auf die regulierende Wirkung des LoiCadre und seiner Ausführungsvorschriften verlassen zu können. An erster Stelle hatte die Reform der Wirtschaft gestanden. Das vorübergehend gelockerte Außenhandelsmonopol des Staates wurde in vollem Umfang wiederhergestellt. Sämtliche Konzessionen für den Privathandel wurden für ungültig erklärt und die Erteilung neuer Konzessionen von der Erfüllung relativ schwieriger Voraussetzungen (Solvenz, Eignung, Berufsethos!) abhängig gemacht, die Zahl der zugelassenen Händler drastisch verringert (in Conakry um vier Fünftel), der Warenverkauf außerhalb der behördlich genehmigten Geschäftslokale mit schweren Strafen bedroht und den Mitgliedern der Regierung sowie den Funktionären und Angestellten des staatlichen Wirtschaftssektors jede direkte oder indirekte Ausübung einer privaten Erwerbstätigkeit, ebenfalls bei Strafe, untersagt. Für Schmuggel von Waren und guineischer Währung wurde Gefängnis von 5 bis 10 Jahren sowie Vermögensbeschlagnahme angedroht, die vorübergehend freigegebene private Suche nach Diamanten wieder für illegal erklärt. Weitere Vorschriften richteten sich gegen Mietwucher und Ausnutzung der Wohnungsnot. Außerdem wurden die auch heute noch tätigen und gefürchteten "commissions de vérification de biens" ins Leben gerufen. Sie erhielten den Auftrag, die seit dem 28. September 1958, dem Unabhängigkeitstag, erworbenen Vermögen der Staats- und Parteifunktionäre sowie der Händler auf ihre Rechtmäßigkeit zu überprüfen und ggf. zu konfiszieren. Einschneidende Vorschriften ergingen auch zur Straffung der Parteiorganisation. In allen Unternehmen und Behörden waren umgehend Betriebsparteiorganisationen zu gründen. Für das Stadtgebiet von Conakry wurde die höchstzulässige Mitgliedszahl auf ein Sechstel der Gesamtbevölkerung festgesetzt und die Ausübung einer produktiven Beschäftigung zur Aufnahmebedingung erhoben. Wer nach 1958 wegen Diebstahl, Unterschlagung, Vertrauensbruch, Subversion und Rassismus verurteilt worden war, verlor, ebenso wie die gesamte Kaufmannschaft, das passive Wahlrecht zu allen Parteiämtern.

95 A. S. Touré, Vingtième Anniversaire et Huitième Congrès, Bd. XVI (1), Conakry 1967, S. $40 \mathrm{ff}$.

96 A. S. Touré, 8 novembre 1964, Conakry 1965, S. $21 \mathrm{ff}$.

97 Gesetze Nr. 25, 26, 28)AN/1964; Dekrete Nr. 427, 456, 466, 477, 513, 514/PRG. YX 
Aber diese Vorschriften, die deutlich machen, welcher Hydra von Widerständen der Entwicklungsstaat im allgemeinen und der progressistische Entwicklungsstaat im besonderen gegenübersteht, reichten nicht aus. Während des Jahres 1967/68 verschärfte sich die Auseinandersetzung mit dem Kleinbürgertum zur Klassenkampfsituation, und das Regime, das sich jahrelang geweigert hatte, dies zu tun, bekannte sich anläßlich des VIII. Kongresses der Einheitspartei im Herbst 1967 ausdrücklich zur "lutte de classes“ als einer revolutionären Waffe.

Ein Jahr später, am 8. November 1968, dem 4. Jahrestag des Loi-Cadre (Le 8 novembre ne saurait être un feu de paille ${ }^{{ }_{98}}$ ), sprach Sékou Touré vom bevorstehenden Kampf der "classe du Peuple“ gegen die "classe des traîtres à la Nation" und verkündete 12 weitere Loi-Cadre-Vorschriften. Sie signalisieren 12 weitere wunde Punkte des Regimes: Beschränkung einer Verwendung im Auswärtigen Dienst auf maximal drei Jahre; Einführung einer jährlichen "conférence de la bouche ouverte" in den Parteiorganisationen; Bedrohung aller Funktionäre, die über ihre Verhältnisse leben, mit der fristlosen Entlassung; Beschränkung des Personenkreises, dem bei Auslandsreisen die Mitnahme von Devisen gestattet ist, auf die Werktätigen; Androhung empfindlicher Strafen für defizitäre Verwaltung öffentlicher Mittel; ebenso für Duldung von Grenzschmuggel, für betrügerische Machenschaften im Zusammenhang mit der Warenverteilung, für illegale EheschlieBung (Mehrehe), für Amtsdelikte in Erbschaftssachen, für die Preisgabe von Dokumenten oder Informationen der Partei bzw. des Staates; Errichtung eines Staatsmonopols für die Vermittlung von Häusern und Dienstleistungen an Ausländer; Auflage an alle in Guinea tätigen Auslandsfirmen, bis zum 8. November 1971 eigene Dienstgebäude zu errichten; Entzug aller Handelskonzessionen im Besitz natürlicher und juristischer Personen ohne guineische Staatsbürgerschaft ... .99. Resümieren wir:

Angesichts dieses immensen Konflikts zwischen Staat und Gesellschaft, ja, zwischen dem Staat und seinen Dienern, ist es kein Wunder, daß die guineische Justiz vor allem dem Schutz des Staates dient bzw. dienen muß. Der Schutz des Bürgers rangiert an zweiter Stelle. Dennoch herrschte in Guinea, wenigstens bis zum November 1970, eine erstaunliche Sicherheit, worin sich dieses Land wohltuend von anderen afrikanischen Ländern unterschied. Was Ibn Batouta Mitte des 18. Jahrhunderts über den Sudan sagte, galt (und gilt hoffentlich bald wieder) ebenso für das Guinea der sechziger Jahre: „.. . De toute l'étendue du pays, il règne une sécurité parfaite; on peut y demeurer et voyager sans craindre le vol ou la rapine ..." ${ }^{* 100}$.

98 HOROYA Nr. 1580 v. 13./14. Okt. 1968.

99 Diese Vorschriften erhielten bis auf die letzte im Januar 1969 Gesetzeskraft (s. J. O. R. G. Jgh. 1969, Nr. 9 v. 1. Mai 1969, S. 88 ff.).

100 Ibn Batouta, Voyage au Soudan (i. d. frz. Ubs. des Barons v. Slane), Paris 1843. 